\title{
Tail risk connectedness between US industries
}

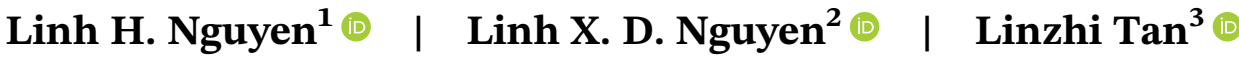

${ }^{1}$ De Montfort University, Leicester Castle Business School, Leicester, UK

${ }^{2}$ University of Leicester, School of Business, Leicester, UK

${ }^{3}$ Nottingham Trent University, Nottingham Business School, Nottingham, UK

\section{Correspondence}

Linh H. Nguyen, De Montfort University, Leicester Castle Business School, The Newarke, Leicester, LE1 9BH, UK.

Email: linh.nguyen@dmu.ac.uk

\begin{abstract}
We use the Least Absolute Shrinkage and Selection Operator (LASSO) quantile regression technique to construct and analyse the complete tail risk connectedness network of the whole US industry system. We also investigate the empirical relationship between input-output linkages and the tail risk spillovers among US industries. Our findings identify the tail-risk drivers, tail-risk receivers, and tail-risk distributors among industries and confirm that the actual trade flow between industries is a major driver of their tail risk connectedness.
\end{abstract}

\section{KE Y W O R D S}

business linkage, input-output, quantile regression, tail risk network, tail risk spillovers

J EL C L A S S I F I C A T I O N

C21; C51; C63; G10; G12; G18; G32; L14; L52

\section{1 | INTRODUCTION}

Fat tail has long been a well-recognized feature of asset returns. Many studies over the last decade have demonstrated that tail risk is an important price determining factor (see Bali, Demirtas, \& Levy, 2009; Bollerslev \& Todorov, 2011; Chabi-Yo, Ruenzi, \& Weigert, 2018; Harris, Nguyen, \& Stoja, 2019; Huang, Liu, Rhee, \& Wu, 2012; Kelly \& Jiang, 2014; Meine, Supper, \& Weib, 2016; among others). Tail risk significantly affects returns at both market level and individual security level. Therefore, monitoring and predicting tail risk play a central role in risk management.

Numerous evidences in the literature show strong connectedness between returns of different assets, especially during distress time. Ang and Chen (2002) demonstrate that the comovement of the US stocks and the aggregate market is greater for downside moves than for upside moves, and the difference is significantly higher for extreme movements. Kenourgios, Samitas, and
Paltalidis (2011) document significant contagion effects between international markets during distress periods, as shown by the jumps in the correlations of stock markets in the well-known financial crises over the last few decades. Madaleno and Pinho (2012) use continuous wavelet analysis to show the contagion between international stock markets during crisis periods. Cappiello, Gérard, Kadareja, and Manganelli (2014) use quantile regression to construct the probability of coexceedances between international equity market returns for different quantile levels and examine the dynamics of the probability conditional on economic indicators. Their results confirm the increase in the comovement of equity markets in distress periods, and the change is significantly more pronounced for left-tail comovement than right-tail comovement.

A number of studies have documented the tail risk interdependence at different aggregation levels, including country, industry, and firm levels. The most popular strand in this literature is, perhaps, the tail risk 
connectedness between countries, for example Kenourgios et al. (2011) and Cappiello et al. (2014) mentioned above. Li and Giles (2015) use a multivariate generalized autoregressive conditional heteroskedasticity model to examine both volatility and shock spillovers between developed and emerging international stock markets. Other studies at the country level are Bae, Karolyi, and Stulz (2003), Hartmann, Straetmans, and De Vries (2004), Hong, Liu, and Wang (2009), Christiansen and Ranaldo (2009), Beine, Cosma, and Vermeulen (2010), among others.

At industry level, research on tail risk interrelationship tends to centre around the financial sector. Adams, Füss, and Gropp (2014) use a system of quantile regressions of Value-at-Risk (hereafter VaR) to investigate the tail risk interdependence between four types of financial services, including commercial banks, investment banks, hedge funds, and insurance companies. They show that commercial banks and hedge funds play important roles in the tail risk transmission between financial institutions. Wang, Xie, He, and Stanley (2017) develop measures of tail risk connectedness for four sectors, namely banks, diversified financials, insurance, and real estate. Their measures are based on the tail risk linkages between institutions across sectors, which are estimated using the Granger causality test for VaR proposed by Hong et al. (2009). Chiu, Pena, and Wang (2015) examine the coexceedances of US real sectors with the financial sector and report significant tail risk spillover from the financial sector to many other sectors. The spillover effect is dependent on industry characteristics such as competition, debt financing, valuation, and investment level. Pouliasis, Kyriakou, and Papapostolou (2017) is among a handful of studies that examine the tail risk linkages between non-financial industries. Using Hong et al. (2009) causality test for VaR exceedance, they report the prevalent left tail spillovers between consumer service industries. In similar spirit, Pouliasis, Papapostolou, Kyriakou, and Visvikis (2018) report strong tail risk spillover between segments of US shipping sectors. Reboredo (2015) finds evidence of the tail dependence between oil and energy sectors.

Studies on tail risk linkages at firm level remarkably focus on financial firms (Betz, Hautsch, Peltonen, \& Schienle, 2016; Billio, Getmansky, Lo, \& Pelizzon, 2012; Hartmann, Straetmans, \& De Vries, 2005; Hautsch, Schaumburg, \& Schienle, 2014; Hautsch, Schaumburg, \& Schienle, 2015; among others). This is not surprising since firms in financial sector are strongly connected and the risk of systematic collapse is high. As shown in Härdle, Wang, and Yu (2016), the term "too connected to fail" becomes relevant for financial firms. In addition to the tail risk interdependence among firms, many studies examine the contribution of the institutions to the tail risk of the financial system, which is known as the systemic risk. A review on systemic risk literature is available in Benoit, Colliard, Hurlin, and Pérignon (2017).

The above discussion shows that, apart from the investigation in the financial sector, the tail risk connectedness has received little attention at the industry and firm level. Thus, our study contributes to this strand of literature by constructing a complete tail risk connectedness network between all industries in the US economy. We use the Least Absolute Shrinkage and Selection Operator (LASSO) quantile regression technique in our study. LASSO quantile regression is developed by Belloni and Chernozhukov (2011) and applied in the construction of the financial network tail risk spillover by Hautsch et al. (2015). The most important feature of this method is that it filters out non-relevant regressors in a highdimensional quantile regression and still consistently estimates the coefficients of the retained relevant regressors. Thus, it enables the high-dimensional investigation of the whole US industry system in our study where we simultaneously model the impact of every industry's tail risk on the tail risk of other industries, controlling for both macroeconomic variables and industry specific characteristics. To our knowledge, this study is the first one to construct and analyse the empirical tail risk connectedness network of the whole US industry system.

Understanding the tail risk interdependence between all industries in the economy is essential for policy makers, business managers, and investors. Several studies show that the shock spillovers between industries can lead to the aggregate fluctuation of the entire economy (see Gabaix, 2011; Long \& Plosser, 1983; Shea, 2002; among others). Thus, by identifying the most important shock-driving industries, the most shock-sensitive industries, as well as possible channels of shock transmissions in the economy, policy makers can properly regulate relevant industries and have prompt actions to prevent the snowball effect of industries' shocks which can potentially destabilize the whole system. Firms can make better decisions when trading with their partners in different industries, by observing and predicting shocks transmitted to and from their partners. For investors, especially fund managers, knowledge about the tail risk interdependence network of the whole economic system is essential not only for predicting the tail risk of individual securities, but also for managing the risk of their portfolio. For example, if their portfolio mainly consists of stocks in highly tail risk connected industries, their tail risk is undiversifiable. If investors ignore this linkage, they are likely to underestimate the total risk of the portfolio and cannot deliver the 
desired risk target. Thus, understanding the tail risk connectedness network would benefit various stakeholders in the economy.

In addition to constructing the tail risk connectedness network, we move one step further to demonstrate how this network is influenced by the actual business linkages between industries. We hypothesize that the actual trade flow between industries is a major driver of their tail risk connectedness. We utilize the Input-Output Accounts provided by the US Bureau of Economic Analysis (BEA) to quantify the strength of the supplier-customer linkages, following the method of Becker and Thomas (2011) and Ahern and Harford (2014). Specifically, we measure the role of an industry in the supplier and customer profiles of its trading partners. We then carry out a cross-sectional regression to examine the extent to which these business linkage variables explain the tail risk spillover coefficients obtained from the tail risk connectedness network. This investigation reveals the economic rationale underlying the structure of the tail risk connectedness network.

This investigation of our paper contributes to a strand in the literature regarding the impact of actual business linkages on various aspects of the stock market performance. For example, at international level, Forbes and Chinn (2004) show return spillovers in stock and bond markets across countries are significantly influenced by bilateral trade flows. At industry level, Ahern (2013) finds evidence that industry linkages affect stock returns. Industries which are more central in the network have higher risk due to higher exposure to sectoral shocks and, therefore, require a positive risk premium. Acemoglu, Ozdaglar, and Tahbaz-Salehi (2017) develop a theoretical model for an economy with sectoral input-output linkages and show that the level of the interconnection between industries plays a key role in economic shock spillovers among industries. At firm level, Cohen and Frazzini (2008) show that customers' returns can forecast subsequent stock returns and operating incomes of their suppliers. Although some papers examine the impact of supplier-customer relationship on the interdependence of stock returns and volatility at different levels, the impact of business linkages on tail risk spillovers has gained far less attention. This paper, to our knowledge, is the first one to examine the empirical relationship between input-output linkages and the tail risk spillovers.

Our empirical results reveal a complicated tail risk connectedness network between industries. Furthermore, we find significant impact of the actual business linkages on the tail risk spillovers among industries. Specifically, the customer roles of industries significantly influence the spillover coefficients between industries. When an industry is a larger customer to the other industry, they tend to have stronger tail risk connections. We also observe that business linkages account for the majority of the explanatory power of the cross-sectional regression, suggesting that business linkage is the main driver of the tail risk connectedness network. Our results are robust to both normal and distress periods, different extreme levels of tail risk, and restricted samples of nonfinancial industries and closely linked industries.

The remainder of this paper is organized as follows. Section 2 discusses the tail risk connectedness between US industries using the LASSO quantile regression. Section 3 describes the construction of business linkage variables from the Input-Output Accounts, and the impact of business linkages on tail risk spillovers. Section 4 reports robustness checks and Section 5 concludes.

\section{2 | TAIL RISK CONNECTEDNESS}

\section{1 | LASSO quantile regression}

The use of quantile regression to capture tail risk is wellestablished in the literature (see, e.g., Adrian \& Brunnermeier, 2016; Giglio, Kelly, \& Pruitt, 2016; among others). To model the tail risk connectedness of the whole US industry system, we follow Hautsch et al. (2015) to use the LASSO quantile regression developed by Belloni and Chernozhukov (2011). Specifically, we estimate a quantile regression equation showing how the tail risk of an industry $i$ returns is explained by the loss exceedance (i.e., returns lower than a pre-determined tail threshold) of each of the other industries, the lagged returns of industry $i$, industry $i$ 's specific characteristics, and macroeconomic variables. As argued by Hautsch et al. (2015), the advantage of this approach is that it allows us to investigate the tail risk connectedness between all industries in the economy.

The tail risk of an industry at time $t$ is measured by the VaR of its returns at that time, which is the quantile corresponding to the VaR significance level of the conditional distribution of the industry returns at time $t$ :

$$
\operatorname{VaR}_{q, t}^{i}=Q_{q, t}^{i}
$$

and $Q_{q, t}^{i}$ satisfies

$$
P\left(X_{t}^{i} \leq Q_{q, t}^{i}\right)=q
$$

where $V a R_{q, t}^{i}$ is the Value-at-Risk of industry $i$ at $q$ significance level; $Q_{q, t}^{i}$ is the $q$-quantile of the conditional distribution of $X_{t}^{i}$ - the returns of industry $i$ at time $t$. Similar 
to Hautsch et al. (2015), we use $q=5 \%$ quantile in our main investigation. Other significance levels of tail risk (1 and $10 \%$ quantile) are examined in our robustness check discussed in Section 4. It should be noted that, for the convenience of the interpretation of the tail risk spillover coefficients in our paper, we define VaR in terms of industry returns rather than industry loss. Thus, a more negative VaR implies higher tail risk.

The quantile regression equation of industry $i$ is given as:

$$
V a R_{q, t}^{i}=\alpha^{i}+\boldsymbol{\beta}^{i} \boldsymbol{C}_{t-1}^{i}+\boldsymbol{\gamma}^{i} \boldsymbol{M}_{t-1}+\boldsymbol{\theta}^{i} \boldsymbol{E}_{t}^{-i}+\omega^{i} X_{t-1}^{i}
$$

where $\boldsymbol{C}_{t-1}^{i}$ is the lagged specific factors of industry $i, \boldsymbol{M}_{t}$ ${ }_{-1}$ is the lagged macroeconomic variables, $X_{t-1}^{i}$ is the lagged return of industry $i$, and $\boldsymbol{E}_{t}^{-i}$ is the loss exceedance of all other industries in the economy except industry $i$. The loss exceedance of an industry $j$ is defined as:

$$
E_{t}^{j}=\left(\begin{array}{c}
0, X_{t}^{j} \geq \text { unconditional } 10 \% \text { sample quantile of } X^{j} \\
X_{t}^{j}, \text { otherwise }
\end{array}\right)
$$

In Equation (4), we follow Hautsch et al. (2015) to use the $10 \%$ sample quantile for loss exceedance in all investigations. ${ }^{1}$ The coefficient $\theta_{j}^{i}$ in Equation (3) shows the level of the tail risk spillover from industry $j$ to industry $i$. Higher $\theta_{j}^{i}$ indicates that when industry $j$ is in a more distress situation (i.e., its return gets more negative), the VaR of industry $i$ reduces by a larger amount, implying higher industry $i$ 's tail risk. In short, higher coefficient $\theta_{j}^{i}$ means stronger tail risk spillover from industry $j$ to industry $i$.

Equation (3) is estimated using Belloni and Chernozhukov (2011) LASSO quantile regression method. First, the irrelevant regressors of the equation are determined as any regressor whose estimated coefficient from the $l_{1}$-penalized quantile regression has the absolute value smaller than a predetermined threshold. We follow Hautsch et al. (2015) to choose the cut-off threshold of 0.0001 . Given a quantile regression of variable $X^{i}$ on the set of demeaned regressor $\boldsymbol{W}^{i}$, the estimated parameters $\tilde{\xi}^{i}$ of the corresponding $l_{1^{-}}$ penalized quantile regression are the ones that minimize:

$\frac{1}{T} \sum_{t=1}^{T}\left(q-I\left(X_{t}^{i} \leq \boldsymbol{W}_{t}^{i} \boldsymbol{\xi}^{i}\right)\right)\left(X_{t}^{i}-\boldsymbol{W}_{t}^{i} \xi^{i}\right)+\lambda \frac{\sqrt{q(1-q)}}{T} \sum_{k=1}^{K} \hat{\sigma}_{k}\left|\xi_{k}^{i}\right|$

where $I(\cdot)$ is the indicator function that equals 1 when the statement inside the bracket is true and 0 otherwise,
$T$ is the number of observations in the estimation sample, $K$ is the number of regressors in $\boldsymbol{W}^{i}, \xi_{k}^{i}$ is the $k^{\text {th }}$ element of the coefficient set $\xi^{i}$, and $\hat{\sigma_{k}}$ is the standard deviation of the $k^{\text {th }}$ regressor, which could be estimated as

$$
\sqrt{\frac{1}{T} \sum_{t=1}^{T}\left(W_{t, k}^{i}\right)^{2}}
$$

In Equation (5), $\lambda$ is the penalty parameter and a higher level of $\lambda$ means more variables would be eliminated. $\lambda$ is determined specific to each industry in a data driven way that maximiszes the backtesting performance of the estimated VaR of the industry. Details about this procedure are provided in Appendix A. The coefficients of the retained relevant regressors will be then estimated consistently using a normal quantile regression of the dependent variable on the relevant regressors, which is referred to as the post-LASSO regression. The value of the component $\theta_{j}^{i}$ in the coefficient vector $\boldsymbol{\theta}^{i}$ in Equation (3) equals the value of the coefficient associated with industry $j$ in the post-LASSO regression if industry $j$ is retained as a relevant regressor, and 0 otherwise.

After estimating Equation (3) for every industry in the system, we construct the tail risk connectedness matrix $\boldsymbol{A}=\left\{A_{i j}\right\}$ where the entry of row $i$ and column $j$, $A_{i j}$, equals $\theta_{j}^{i}$. For every pair of industries, there are two tail risk connectedness coefficients: $\theta_{j}^{i}$ showing the spillover from $j$ to $i$, and $\theta_{i}^{j}$ showing the spillover from $i$ to $j$. From the connectedness matrix, we obtain the tail risk in-degree of an industry $i$ as the number of industries which transmit tail risk to industry $i$, and the tail risk out-degree of industry $i$ as the number of industries which receive tail risk from industry $i$. The tail risk netdegree of industry $i$ is the difference between its outdegree and in-degree, showing whether the industry $i$ is a tail-risk driver or a tail-risk receiver in the system. We calculate the total number of connections in matrix $\boldsymbol{A}$ to capture the total level of connectedness of the whole system.

\section{2 | Data}

We construct the industry returns as the market capital weighted average returns of all stocks traded in NYSE, AMEX, and NASDAQ with share codes 10 and 11 from the Centre for Research in Security Prices (CRSP) database. We classify stocks into industries based on the North American Industry Classification System (NAICS) codes, which are also used in the Input-Output database provided by the Bureau of Economic Analysis (BEA). This facilitates our analysis on the relationship between 
tail risk connectedness and business linkages among industries which we discuss in Section 3. We use the Input-Output Accounts at the summary level which consists of 71 industries in the US economy. After eliminating industries in the government sector and industries without observations from CRSP database, we are left with 59 industries for our investigation. The list of industries and their corresponding abbreviations are provided in Appendix B. We use weekly returns during a 12-year period from January 2005 to December 2016.

Regarding macroeconomic variables, similar to Hautsch et al. (2015) and Adrian and Brunnermeier (2016), we use the implied volatility index, the short-term liquidity spread (measured as the spread between the 3-month collateral repo rate and the 3month Treasury Bill rate), the change in 3-month Treasury Bill rate, the change in the slope of the yield curve (measured as the spread between the 10-year Treasury Note and the 3-month Treasury Bill), the change in credit spread between BAA rated bonds and the 10-year Treasury Note, and the CRSP index returns. We obtain the implied volatility index VIX from the Chicago Board Options Exchange, the 3-month collateral repo rate from Bloomberg, and the BAA bond rate, the 10-year Treasury Note rate, and the 3-month Treasury Bill rate from the Federal Reserve Bank of St. Louis.

Given the limited availability of accounting ratios for the whole US industry system, we construct a database for industry characteristics based on the accounting data of all companies in Compustat database. Specifically, we sort the companies in Compustat by their NAICS codes, then aggregate the accounting data of all firms in an industry to represent the characteristics of the whole industry. ${ }^{2}$ In line with Hautsch et al. (2015), we control for leverage (total asset over total book value of equity), maturity mismatch (short term debt net of cash, divided by total liabilities), size (natural logarithm of total asset), and daily volatility over a week in the quantile regression. In order to obtain weekly observations of quarterly accounting ratios, similar to Hautsch et al. (2015), we use interpolation with cubic splines. Appendix $\mathrm{C}$ provides the summary statistics of all industry data in our research.

\section{3 | Tail risk connectedness network between US industries}

We estimate the LASSO quantile regression for every industry to obtain the tail risk spillover coefficients. We then construct the connectedness matrix $\boldsymbol{A}$ between all industries in the US economy from the estimated coefficients. For a network of 59 industries, there are 3,422 possible pairwise directional spillovers. We observe 694 significant tail risk spillovers, which is about $20 \%$ of the total possible directional connections, chosen as relevant regressors by the LASSO procedure. This is consistent with the structure of the US economy in which each industry, by its nature, is only closely linked to a few related partner industries. Further evidence for this will be provided in the degree analysis and the business linkage investigation.

Figure 1 presents a graph which illustrates the tail risk connectedness network between US industries. An arrow with the direction from industry $i$ to industry $j$ implies that industry $i$ is selected by the LASSO quantile regression as a relevant driver of the VaR of industry $j$. If $i$ is eliminated by the LASSO quantile regression in explaining the $\operatorname{VaR}$ of $j$, there is no arrow from $i$ to $j$. The thickness of the arrows illustrates the level of tail risk spillovers. A thin (light grey) arrow represents the tail risk spillover coefficient with absolute value smaller than 0.4 , a medium-size (dark grey) arrow represents the coefficient with absolute value from 0.4 to 0.8 , and a thick (black) arrow displays the coefficient with absolute value larger than $0.8 .^{3}$ The majority (93.3\%) of the tail risk connectedness is weak, as shown by a large number of thin arrows in the graph. Some of the strongest tail risk spillovers identified in the network are those from Administrative and support service (ADM) to Social Assistance (SA) with the spillover coefficient of 1.2, from Insurance carriers and related activities (INS) to Legal services (LGL) with the spillover coefficient of 1.19, and from Other transportation and support activities (OTP) to Air transportation (ARTP) with the spillover coefficient of 1.04 .

In addition to pairwise spillovers, we also observe the distributions of the connectedness degree measures of US industries. Figure 2 plots the histograms of the outdegree, in-degree and net-degree measures. The average out-degree is about 12 , implying that shock to an industry can transmit to 12 other industries on average. This number is reasonable since each industry, due to its business nature, only have direct influence on some closely related partners in the economy. A few industries have the outdegree levels of around 30, suggesting that they have considerably high systemic contribution to the economy. Meanwhile, the in-degree distribution spreads out quite evenly between 0 and 23, implying the sensitivity to tail risk transmission varies significantly across US industries. While some industries are quite vulnerable, receiving shocks from more than 20 other industries in the network, some industries tend not to be affected by tail risk spillovers from others.

Finally, based on the net-degree measure, an industry can be considered as a risk driver, risk receiver, or risk distributor. Risk drivers are industries with highly 


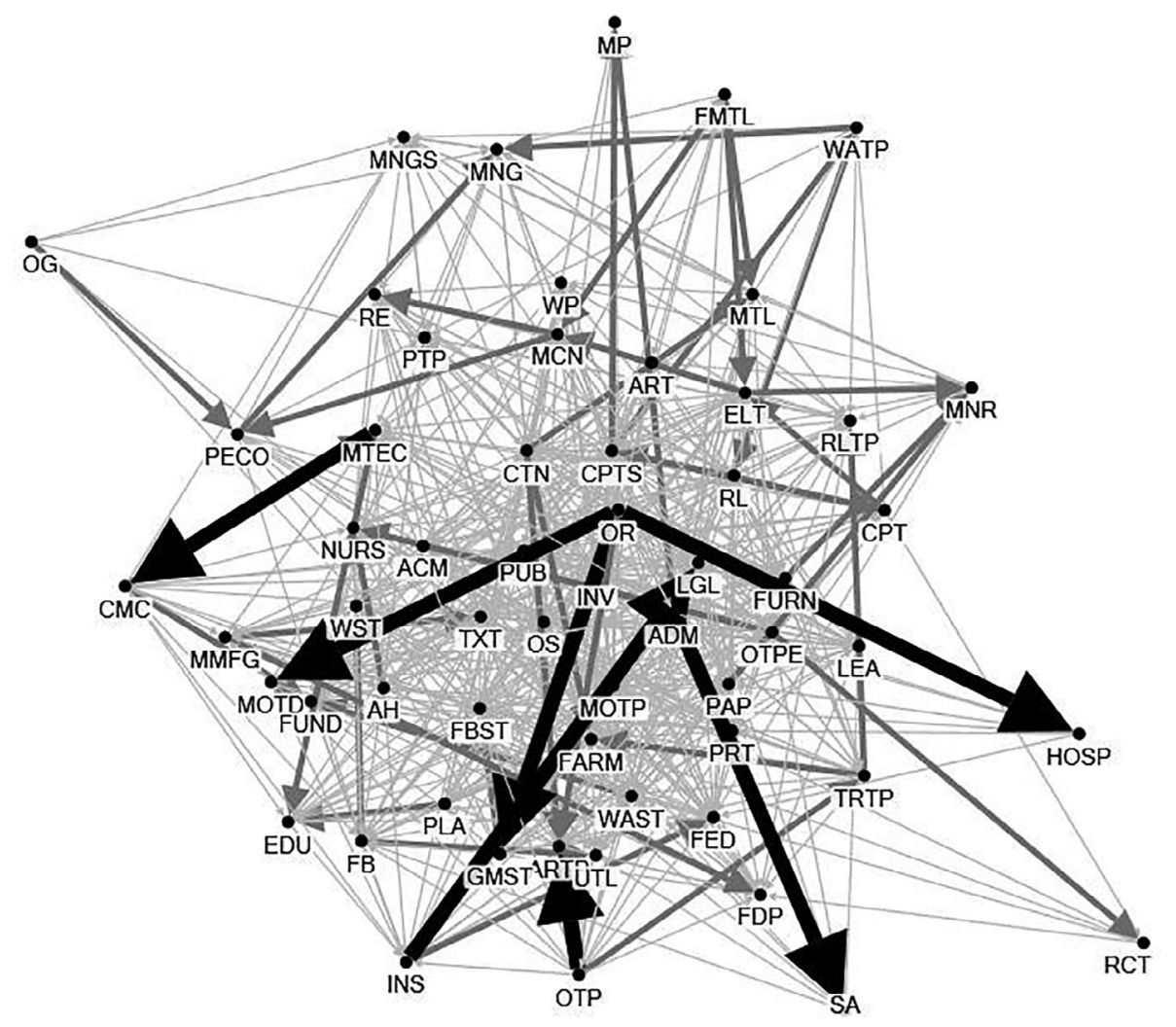

F I G URE 1 Tail risk connectedness network between US industries. This graph shows the tail risk connectedness between 59 US industries estimated from the LASSO quantile regression. Thick black arrows show the spillovers with the absolute values of the estimated coefficient greater than 0.8. Medium dark grey arrows show the spillovers with the absolute values of the estimated coefficient from 0.4 to 0.8 . Thin light grey arrows show the spillovers with the absolute values of the estimated coefficient less than 0.4 . The direction of an arrow shows the direction of the spillover
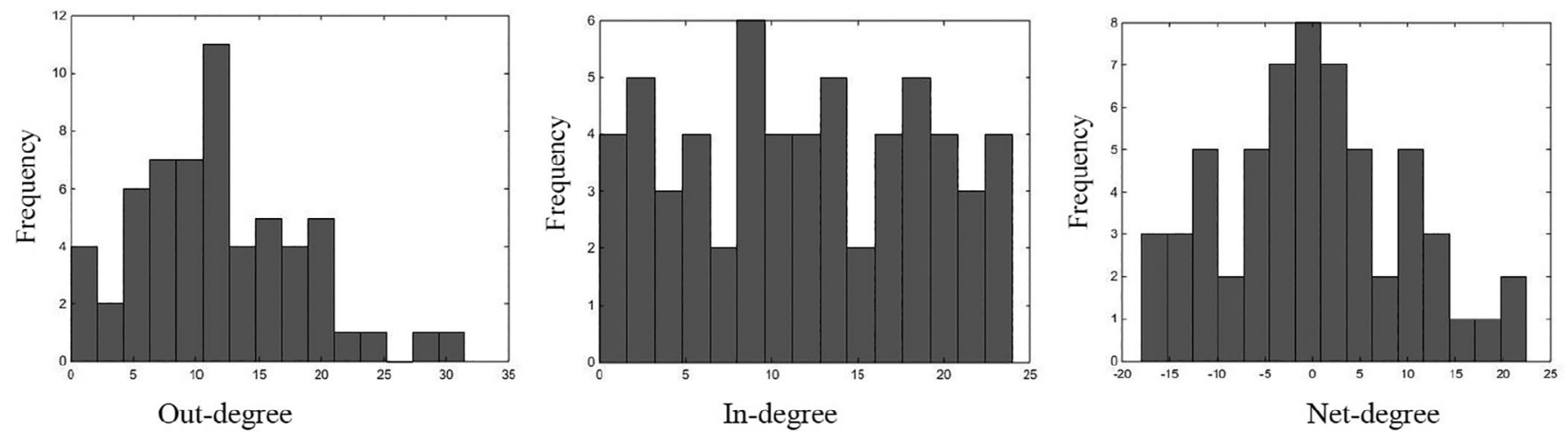

F I G URE 2 Distributions of the degree measures of 59 US industries. This figure shows the histograms of the tail risk connectedness degree measures of 59 US industries, calculated from the tail risk spillovers estimated from the LASSO quantile regression. Panel 1, 2 and 3 plots the out-degree, in-degree, and net-degree, respectively

positive net-degree, whose risk can significantly affect a large number of other industries while they are relatively unaffected by the others' shocks. Risk receivers are industries with highly negative net-degree. These industries are sensitive to shocks transmitted from other industry partners. Industries with net-degree around 0 are considered as risk distributors. They receive tail risk from other industries and amplify the risk in the system by transmitting it to others. As can be seen in the third chart of Figure 2, most industries act as risk distributors in the network.

Table 1 reports top five and bottom five industries for each tail risk connectedness degree measure. Firstly, in term of the out-degree measure, Construction (CTN), Other retail (OR), and Electrical equipment, appliances, and components (ELT) are the top industries whose tail risk spills over to about half of the number of industries in the economy. In contrast, Motion picture and sound recording industries (MP) and Food services and drinking places (FDP) affect only one or two other industries. This is justifiable since these industries mainly interact with final users, rather than contributing to the production of other industries in the economy.

Secondly, regarding the in-degree measure, Computer system design and related services (CPTS), Printing and 
T A B L E 1 Tail risk connectedness degree measures - Top and bottom industries

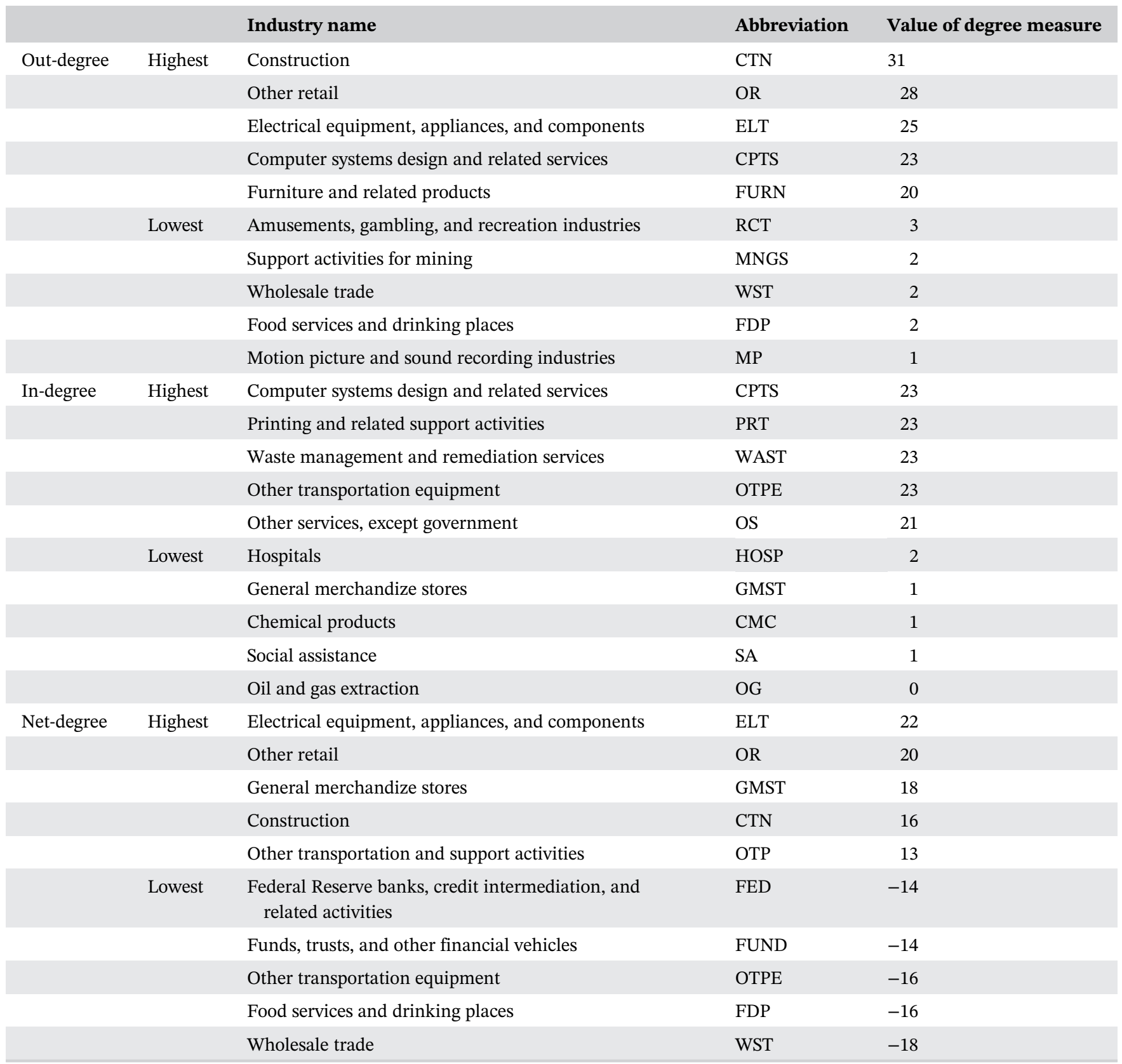

Note: This table shows the top and bottom industries for the tail risk degree measures, including the out-degree, in-degree and net-degree.

related support activities (PRT) and Waste management and remediation services (WAST) are the top industries which receive risk spillovers from 23 other industries, while Social assistance (SA), Chemical products (CMC), and General merchandize stores (GMST) are industries that are affected by only one industry. Oil and gas extraction (OG) is the most tail-risk resistant industry in the economy with a zero in-degree level. In other words, the tail risk of Oil and gas extraction (OG) is not significantly affected by any other industry in the economy. This is not surprising since the risk of this industry tends to be driven by the supply shocks in major oil and gas supplying countries, or the aggregate demand shocks from the economy rather than by shocks from any particular industry. This is consistent with Baumeister and Kilian (2016) who show a number of supply shocks that drive the oil market in the history. Kilian (2009) shows that the main drivers of the oil market are global aggregate demand shocks and precautionary demand shocks.

Thirdly, we observe that the main risk drivers (i.e., industries with the highest net-degree level) are usually the top out-degree industries (e.g., Electrical equipment, appliances, and components (ELT), Other retails (OR), and Construction (CTN)) while the main risk receivers (i. 


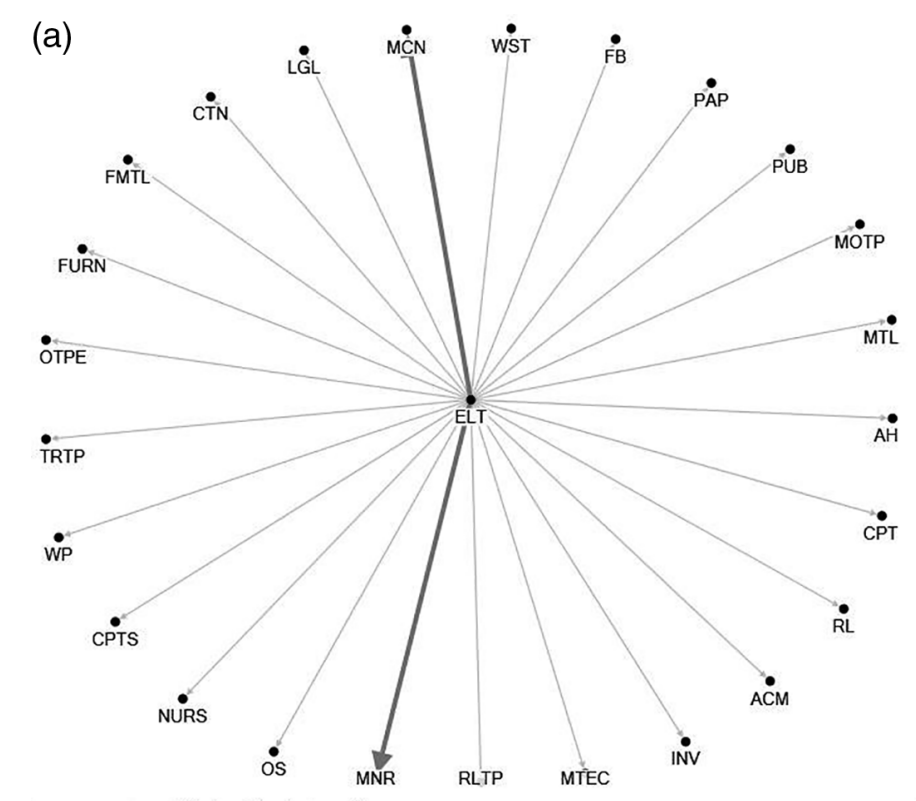

(b)

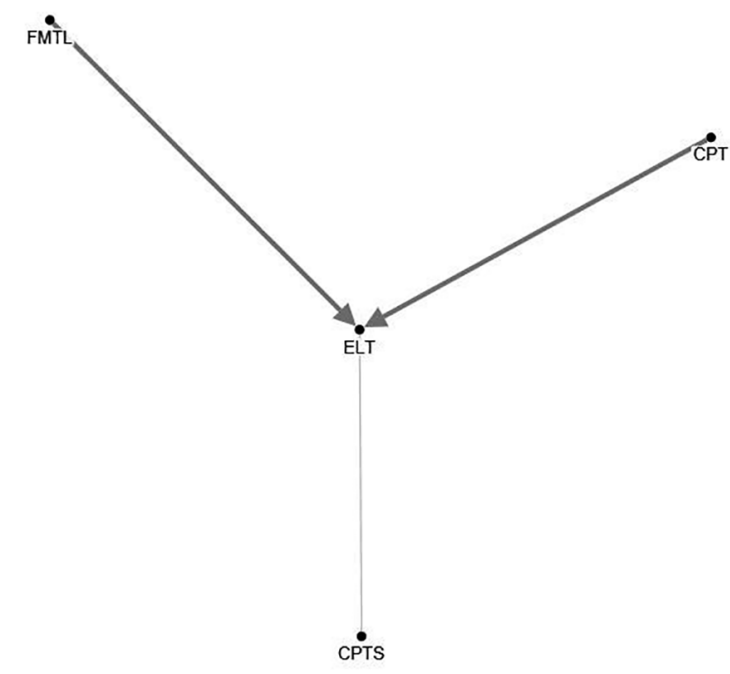

F I G URE 3 Tail risk spillover network of ELT industry. This graph shows the tail risk spillover network of the Electrical equipment, appliances, and components (ELT) industry. ELT takes the role of tail risk transmitter in Panel A and tail risk receiver in Panel B. Dark grey arrows show the spillovers with the absolute values of the estimated coefficient from 0.4 to 0.8 . Light grey arrows show the spillovers with the absolute values of the estimated coefficient smaller than 0.4. The direction of an arrow shows the direction of the spillover

e., industries with the lowest net-degree level) are the bottom out-degree industries (e.g., Wholesale trade (WST) and Food services and drinking places (FDP)). Due to the nature of businesses, shocks to some industries can affect a large number of other industries (high out-degree) while these industries may not be significantly influenced by shock transmission from their partners (low in-degree). Thus, they are the main risk drivers. To demonstrate, the production of Electrical equipment, appliances, and components (ELT) relates to many trading partners, both by using the inputs and producing goods which are essential for other industries. Although it can also receive shocks from others, its shocks are more relevant to other trading partners. On the other hand, some industries tend to receive risks from others. They are quite vulnerable to external shocks (high in-degree); however, their shocks appear to be insignificant to their partners (low out-degree). An example is Wholesale trade (WST) which distributes goods across the economy. It is understandable why its business is significantly driven by the state of the whole economy and this industry tends to be a shock receiver in the network.

The tail risk connectedness matrix is useful for monitoring the tail risk structure of the whole economy, and also the risk of any particular industry. This is especially important for business managers and investors who invest in a specific industry or some related industries. To demonstrate, Figure 3 shows the tail risk connectedness between the Electrical equipment, appliances, and components industry (ELT) and its related industries, where ELT takes the role of risk driver (Panel A) and risk receiver (Panel B). If there is a shock to ELT, investors and managers can quickly identify industries that will be directly affected. In addition, to predict the tail risk of ELT, managers and investors can observe shocks to its main risk drivers (e.g., Fabricated metal products (FMTL), Computer and electronic products (CPT), and Computer systems design and related services (CPTS)).

\section{3 | THE INFLUENCE OF INDUSTRY BUSINESS LINKAGES}

\subsection{Input-Output accounts and business linkage variables}

We measure the strength of the business linkages between industries using the data from the Input-Output (IO) Accounts provided by the Bureau of Economic Analysis. The value of commodity inputs and outputs of every industry in the US economy are reported in two main tables: the Make and the Use tables (for snapshots of these tables see Appendix D). The Make table reports the value of the commodities (in columns) produced by the industries (in rows). The total output of industry $i$, denoted by OUTPUT $_{i}$, is obtained as the sum of all entries in row $i$. The total output of a commodity produced by all industries is the sum of all entries in a column. The Use 
table presents the value of commodities purchased as inputs by industries (or consumed by final users). Commodities are reported in rows while industries are listed in columns. The sum of all entries in a row is the total commodity output while the sum of all entries in a column is the total industry input, denoted by $\mathrm{INPUT}_{j}$ for industry $j$. Total industry input plus the total value added gives the total industry output, presented in the last row of the Use table.

To measure the strength of the supplier-customer relationship between industries, we follow Ahern and Harford (2014) and Becker and Thomas (2011) to construct the CUST and SUPP matrices. First, using information from the Make table, we calculate the subordinate SHARE matrix. Specifically, the element in row $i$, column $c$, denoted $S H A R E_{i c}$, is calculated as:

$$
\text { SHARE }_{i c}=\frac{\text { Make }_{i c}}{\text { Total Supply }_{c}}
$$

where $i$ and $c$ index industry and commodity, respectively. Make $_{i c}$ is the element in row $i$, column $c$ of the Make table, showing the value of commodity $c$ produced by industry $i$. Total Supply $y_{c}$ is the total supply of commodity $c$, which includes the total output of commodity $c$ produced by all the industries plus other components such as imports or changes in inventories. Thus, the SHARE matrix presents the contribution of an industry in the total supply of each commodity in the economy.

Next, we construct the REVSHARE matrix, of which the element in row $i$, column $j$, REVSHARE $i j$, is obtained as:

$$
\operatorname{REVSHARE}_{i j}=\sum_{c=1}^{C}\left(\operatorname{SHARE}_{i c} \times U s e_{c j}\right)
$$

where $\mathrm{SHARE}_{i c}$ (row $i$, column $c$ element of the SHARE matrix) presents the proportion of commodity $c$ produced by industry $i$, and $U s e_{c j}$ (row $c$, column $j$ element in the Use table) shows the value of commodity $c$ used as inputs in the production of industry $j .{ }^{4}$ Therefore, REVSHARE matrix shows the value of all commodities traded between every pair of industries.

Finally, we construct the CUST and SUPP matrices, showing the customer and supplier roles of an industry to another industry, respectively. Specifically, the elements in row $i$, column $j$ in the CUST matrix, denoted by CUST $_{i j}$, and in the SUPP matrix, denoted by $\operatorname{SUPP}_{i j}$, are calculated as:

$$
\operatorname{CUST}_{i j}=\frac{\text { REVSHARE }_{i j}}{\text { OUTPUT }_{i}}
$$

$$
S U P P_{i j}=\frac{R E V S H A R E_{i j}}{I N P U T_{j}}
$$

where REVSHARE $i j$ is the total value of all commodities which industry $j$ purchases from industry $i$, OUTPUT ${ }_{i}$ is the total output value of industry $i$ in the Make table and INPUT $_{j}$ is the total input value of industry $j .{ }^{5}$ Thus, CUS$\mathrm{T}_{i j}$ shows the proportion of industry $i$ 's revenue generated by industry $j$ and $\operatorname{SUPP}_{i j}$ shows the proportion of industry $j$ 's total input purchased from industry $i$.

Table 2 shows the summary statistics of business linkages between industries based on the relationship variables (CUST, SUPP) constructed from the IO tables of 71 industries. We only report the results for 59 industries in our sample. We use the average relationship variables during the 12-year sample period from 2005 to $2016 .{ }^{6}$ For a pair of industries, we obtain four relationship variables (CUST $i j, \mathrm{SUPP}_{i j}, \mathrm{CUST}_{i j}$, and SUP$\mathrm{P}_{j i}$ ). Based on the value of the relationship variables, we classify industry pairs as having weak or close business linkages at different threshold ranging from 1 to $10 \%$. The first row of Table 2 shows that at 1 threshold, 1,106 among 1,711 industry pairs, or $64.6 \%$ of the pairs, have weak linkages, with all relationship variables smaller than $1 \%$. This is justifiable in a developed economy like the US, where industries are well classified, and each industry tends to largely trade with only a few main suppliers and customers. While 359 pairs have at least one main customer (i.e., at least one CUST variable is larger than 1\%), 506 pairs have at least one main supplier (i. e., at least one SUPP variable is larger than $1 \%$ ). In general, 605 pairs have strong linkages, with at least one of the four relationship variables larger than $1 \%$. Obviously, the number of closely linked industry pairs decreases as the threshold increases. At $10 \%$ level, only 41 pairs, or about $2.4 \%$ of the pairs, have strong business relationship. This is consistent with the structure of the tail risk connectedness network. This evidence offers the first clue for the influence of business linkages on tail risk spillovers between industries, which will be examined in the next section.

\section{2 | The influence of business linkages on tail risk spillovers}

We now examine the extent to which the tail risk spillovers are affected by the business linkages between industry $i$ and industry $j$. Specifically, we estimate a cross-sectional regression as follows:

$$
\begin{aligned}
A_{j i}= & \varphi_{0}+\varphi_{1} \mathrm{CUST}_{j i}+\varphi_{2} \mathrm{SUPP}_{i j}+\varphi_{3} \mathrm{CUST}_{i j}+\varphi_{4} \mathrm{SUPP}_{j i} \\
& +\boldsymbol{v}_{i j} \boldsymbol{\delta}+\epsilon_{i j}
\end{aligned}
$$


T A B LE 2 Summary statistics of the business linkages between US industries

\begin{tabular}{|c|c|c|c|c|c|c|c|c|c|c|}
\hline & \multicolumn{10}{|c|}{ Business linkage threshold (percent) } \\
\hline Pairs with weak linkage & 1,106 & 1,361 & 1,489 & 1,549 & 1,588 & 1,622 & 1,640 & 1,654 & 1,663 & 1,670 \\
\hline Pairs with at least one main customer & 359 & 178 & 101 & 72 & 56 & 46 & 39 & 30 & 25 & 22 \\
\hline Pairs with at least one main supplier & 506 & 283 & 179 & 124 & 93 & 64 & 50 & 39 & 31 & 24 \\
\hline
\end{tabular}

Note: This table shows the summary statistics of the business linkages of 1,711 industry pairs based on the relationship variables $\left(\mathrm{CUST}_{j i}\right.$, $\mathrm{SUPP}_{i j}, \mathrm{CUST}_{i j}$, and $\mathrm{SUPP}_{j i}$ ) at different thresholds ranging from 1 to $10 \%$ (in columns). Pairs with weak linkage are pairs with all four relationship variables smaller than the threshold. Pairs with at least one main customer (supplier) are pairs with at least one CUST (SUPP) variable larger than the threshold. Pairs with at least one main customer or supplier are pairs with at least one of the four relationship variables larger than the threshold.

where $A_{j i}$ is the element of the connectedness matrix $\boldsymbol{A}$, showing the tail risk spillover from industry $i$ to industry $j$. CUST $i, \operatorname{SUPP}_{i j}, \mathrm{CUST}_{i j}$, and $S U P P_{j i}$ represent the customer role of $i$ to $j$, the supplier role of $i$ to $j$, the customer role of $j$ to $i$, and the supplier role of $j$ to $i$, respectively. $\boldsymbol{v}_{i j}$ is a row vector of industry characteristics of industry $i$ and industry $j ; \varphi_{0}, \varphi_{1}, \varphi_{2}, \varphi_{3}, \varphi_{4}$ are estimated coefficients, $\delta$ includes all estimated coefficients of the industry specific characteristics; and $\epsilon_{i j}$ is the residual term. We include in $\boldsymbol{v}_{i j}$ the industry characteristics used in the quantile regression of industries. The explanatory variables in the cross-sectional regression in Equation (11) are the average of the characteristic and linkage variables of an industry over the whole sample period. For each pair of industry $i$ and industry $j$, we obtain two spillover coefficients - $A_{i j}$ and $A_{j i}$. Consequently, from the 1,711 industry pairs, we obtain 3,422 cross-section observations. We bootstrap the standard errors of the estimated coefficients with 1,000 resampling to account for the fact that the dependent variables are estimated from the first stage quantile regression. The sign and the significance of the coefficients $\varphi_{1}, \varphi_{2}, \varphi_{3}, \varphi_{4}$ reveal the influence of the actual business linkages between industries on the tail risk spillovers between them.

Table 3 reports the results of the cross-sectional regression. We observe significant impact of business linkages on the tail risk spillovers between industries. We find the tail risk spillover from industry $i$ to industry $j$ is significantly and positively related to the customer roles of the two industries. This means when an industry becomes a larger customer of the other industry, its tail risk tends to spill more strongly to its partner and is also more affected by its partner. The fact that the customer relationship significantly influences the tail risk connectedness between industries reflects the customer-oriented culture of the US business. Moreover, we observe that the business linkage variables account for the majority of the explanatory power of the regression. The inclusion of industry characteristic variables only marginally increases the R-squared of the regression and most of the coefficients are insignificant. This result strongly confirms our hypothesis that the main underlying rationale of the spillover dynamics between industries in the US economy is the actual business linkages between them.

\section{4 | ROBUSTNESS CHECKS}

\section{1 | Tail risk connectedness in different market conditions}

In this section, we examine the tail risk connectedness network between US industries, and how the spillovers are affected by their business linkages in different market conditions. We include a crisis dummy variable as well as its interaction terms with all explanatory variables in the first stage LASSO quantile regression. The crisis dummy $(D)$ takes the value of 1 for weeks starting from January 1, 2007 to December 31, 2009, and 0 otherwise. The coefficients corresponding to the loss exceedance terms capture the tail risk spillover between industries in normal period. The coefficients of the interaction terms between the crisis dummy and loss exceedance show the change in tail risk spillovers between industries in crisis period.

We obtain two tail risk connectedness matrices from the LASSO quantile regression: $\boldsymbol{A}$ is the tail risk connectedness matrix in normal period constructed from the coefficients of the loss exceedance terms, and $\boldsymbol{D A}$ presents the change in $\boldsymbol{A}$ due to crisis. The elements in $\boldsymbol{D A}$ are the coefficients of the interaction terms between the dummy crisis and loss exceedances. We also construct matrix $\boldsymbol{A D A}$ as the sum of $\boldsymbol{A}$ and $\boldsymbol{D A}$ matrices, which shows the value of the spillover coefficients in the crisis 


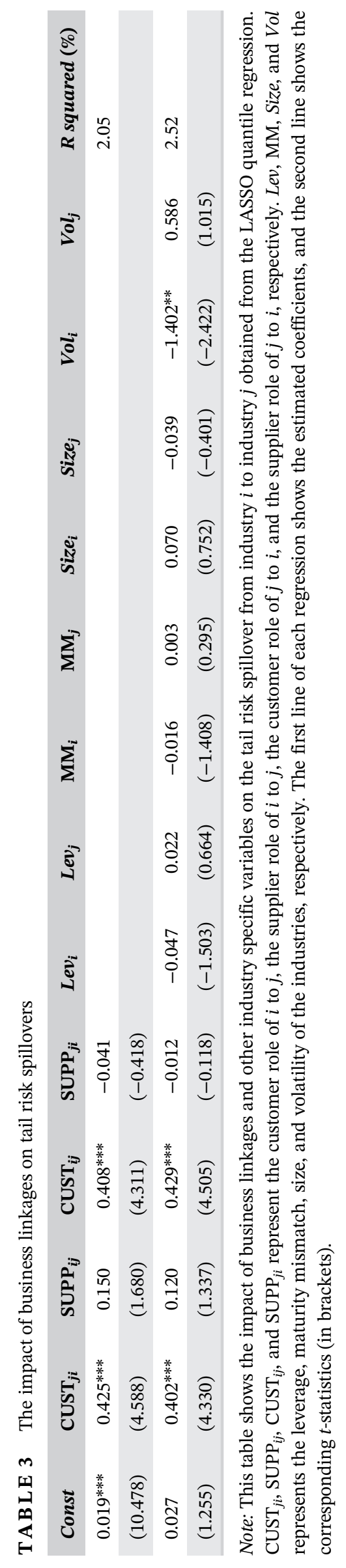




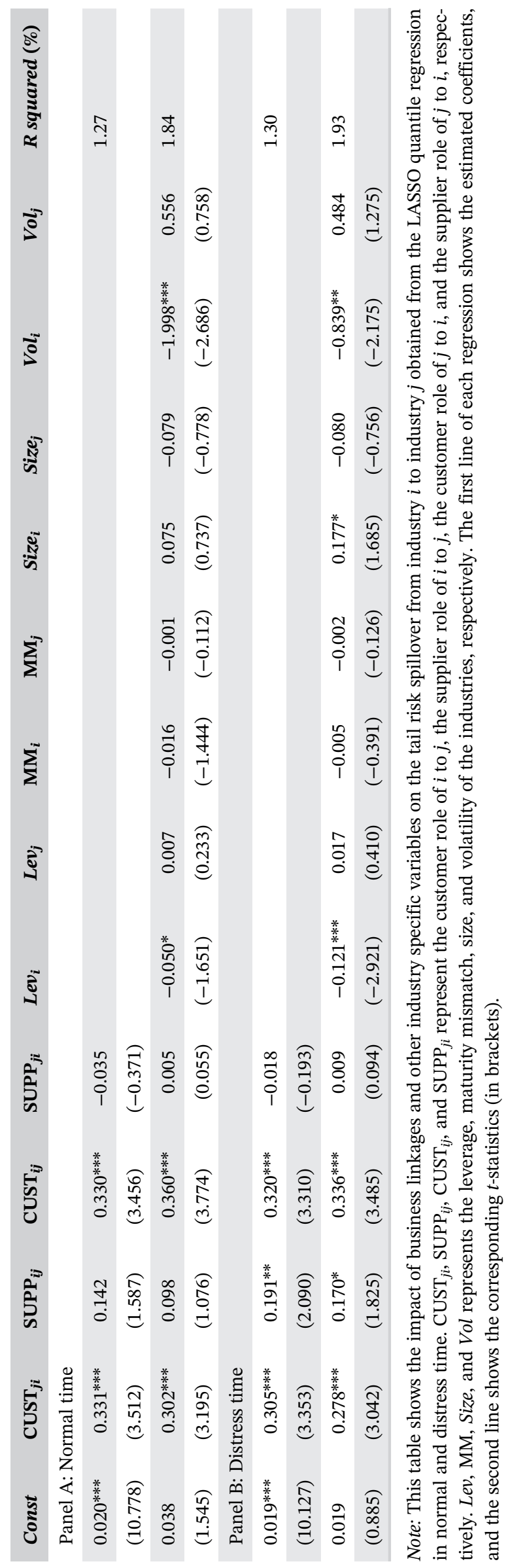


period. This framework can generate several scenarios of the difference of tail risk spillovers between normal time and distress time. First, for a non-zero entry in $\boldsymbol{A}$, we say that the tail risk connectedness changes in crisis time if its corresponding entry in $\boldsymbol{D A}$ is different from zero, and there is no change in the crisis period if its corresponding entry in $\boldsymbol{D A}$ is zero. If the corresponding non-zero entry in $\boldsymbol{D A}$ has the opposite sign and almost similar magnitude with the entry in $\boldsymbol{A}$, the tail risk spillover between the two industries almost disappears in crisis period. Second, for a zero entry in $\boldsymbol{A}$, a corresponding non-zero entry in $\boldsymbol{D A}$ implies that an industry starts to affect its partner in crisis time. Due to the large scale of the $\boldsymbol{A}, \boldsymbol{D A}$, and $\boldsymbol{A D A}$ matrices, we do not report these tables in our paper. The tables are available from the authors upon request.

The results of this investigation show that there are changes in the tail risk transmissions between industries in crisis period. We observe a $5.4 \%$ increase in the number of relevant spillovers, from 608 spillovers in normal time to 641 spillovers in crisis time. No tail risk connectedness disappears in crisis period. In contrast, 57 spillover coefficients change values due to crisis. Taking a closer look at the financial industries (NAICS codes from $52 \mathrm{X}$ to $53 \mathrm{X}$ ) in the crisis period, we observe an average increase of 0.05 in the values of their spillover coefficients. There are only three new spillovers from financial industries to the other industries. Thus, although the tail risk spillovers between the financial industries and other industries increase during crisis, they tend to retain within the established spillover channels rather than spreading out to more industries in the system.

We also examine the influence of business linkages on tail risk spillovers in different market conditions using the cross-sectional regression. Table 4 shows the results of this investigation for normal period (Panel A) and distress period (Panel B). The dependent variables in normal and distress periods are obtained from the matrix $\boldsymbol{A}$ and $\boldsymbol{A D A}$, respectively. The results in Panel A is similar to the standard framework results in Table 3. Specifically, the customer roles of both industries significantly and positively affect the magnitude of tail risk spillovers between them. Panel B confirms the robustness of our results in the distress period, where the customer roles are positive and highly significant. Moreover, in the distress period, the supplier role of an industry to its partner also has a significant and positive impact on the industry's tail risk spillover to its partner. The R-squared is also slightly higher in the distress period regression compared to that of the normal period. This implies that, business linkages can explain the tail risk spillovers among industries more in distress time.

\subsection{The connectedness at different tail risk levels}

Our standard framework investigates the tail risk connectedness and business linkages between US industries at 5\% VaR level. In this section, we check the sensitivity of our results to different tail risk levels, by using 1 and $10 \%$ VaR level. The results of LASSO quantile regressions show stronger risk connectedness between industries at a less extreme level of the tail. The number of relevant tail risk spillover coefficients increases from 574 at $1 \%$ VaR, to 694 at 5\% VaR, and 745 at 10\% VaR. The average outdegree and in-degree of an industry also increase from 9.73 at $1 \%$ VaR to 11.76 and 12.63 at 5 and $10 \% \mathrm{VaR}$, respectively. When the very extreme shock of an industry tends to be generated from its own problem, the tail risk at a higher significance level (i.e., less extreme tail) can be accounted for by other factors, such as spillovers from other industries in the network.

Table 5 reports the results of the cross-sectional regression showing the influence of business linkages on tail risk spillover corresponding to different VaR significant levels. Comparing the results in this table and in Table 3, the R-squared coefficients increase as tail risk significance level increases. Thus, for a less extreme definition of tail risk, not only industries are getting more connected, but their connectedness is also more related to their actual business linkages. We still find the significant impacts of the customer roles of both industries $i$ and $j$ on the tail risk spillover from $i$ to $j$, which is qualitatively similar to our main results.

\section{3 | Business linkages and tail risk spillovers between closely linked industries}

The data we obtain from the SUPP and CUST tables reveal that, while some industry pairs have strong linkages (i.e., at least one industry is the main supplier and/ or main customer of the other industry), many pairs show weak relationship with very small SUPP and CUST variables. Therefore, in this robustness check, we examine the impact of business linkages on tail risk spillovers between closely related industries. We create sub-samples of only pairs of industries in which the value of at least one of the four relationship variables CUST $_{j i}, \mathrm{SUPP}_{i j}$, $\mathrm{CUST}_{i j}$, and $\mathrm{SUPP}_{j i}$ ) is larger than or equal to a certain threshold. Our restricted samples consist of 605,350 , and 222 industry pairs at 1,2, and 3\% threshold, respectively. The results shown in Table 6 are similar to our main results and confirm the relevance of business linkages in explaining the tail risk connectedness. More importantly, 


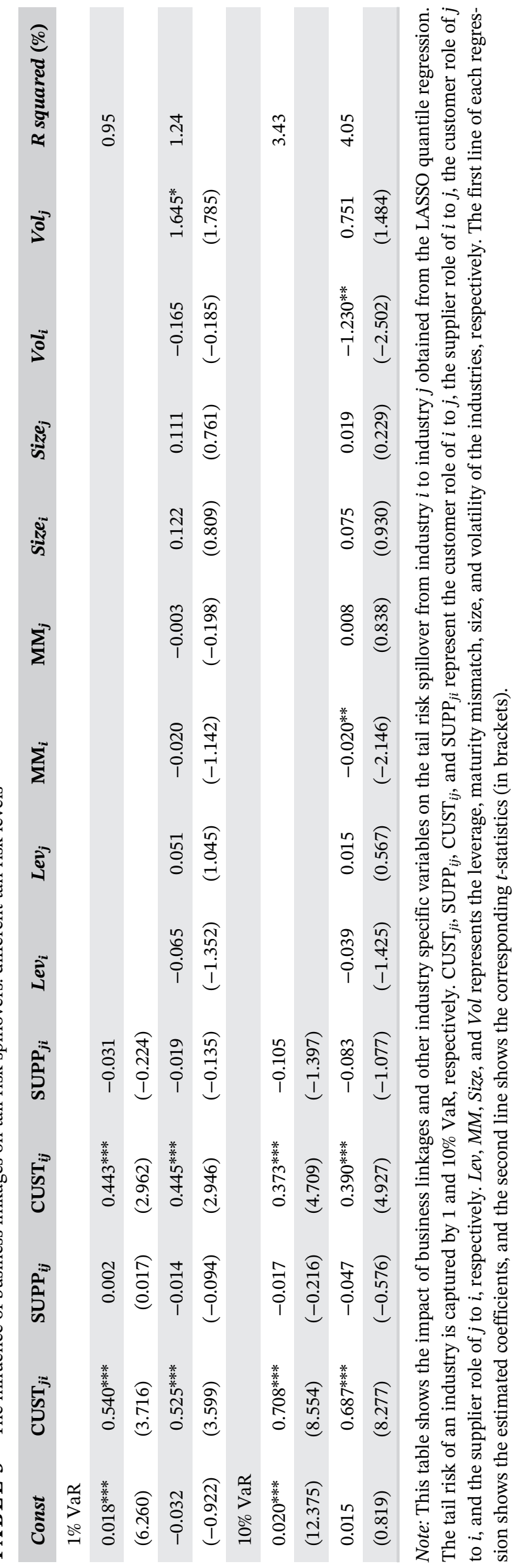




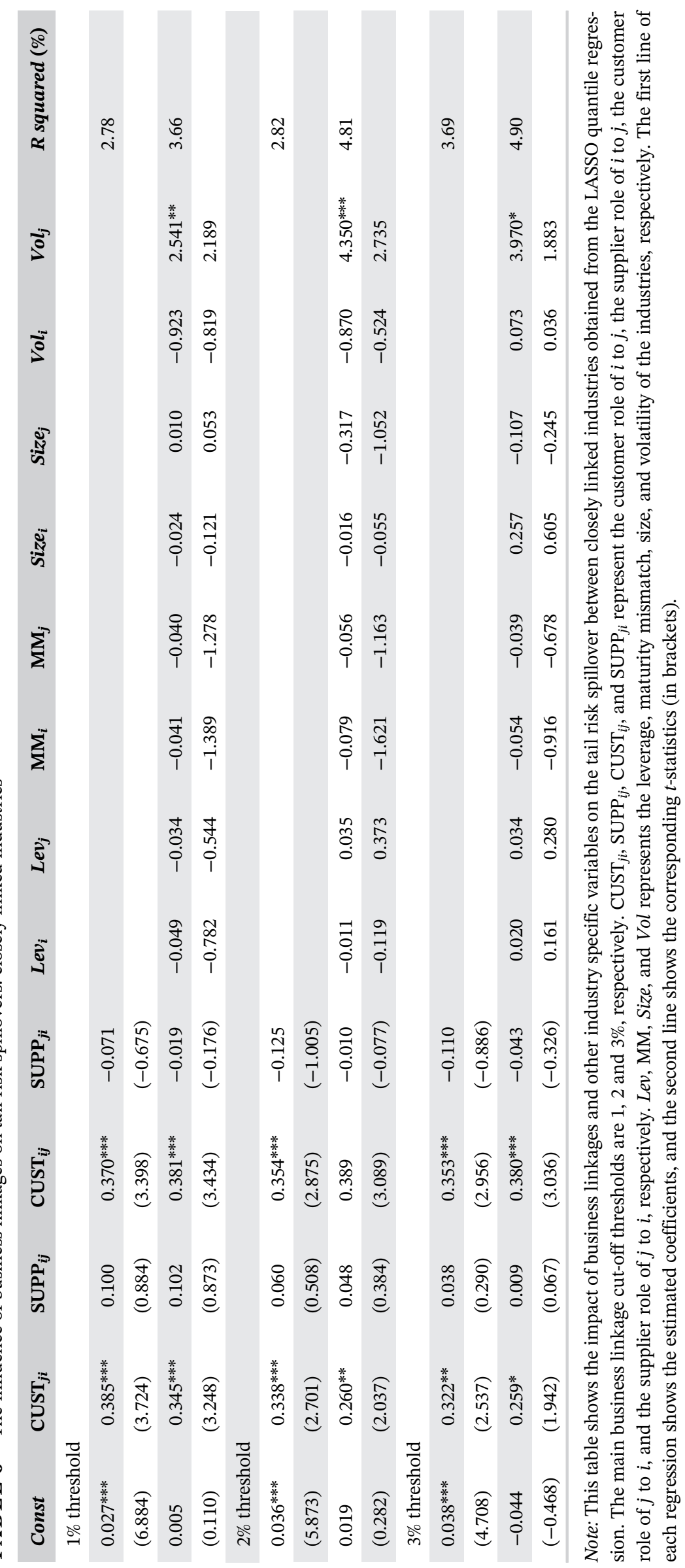




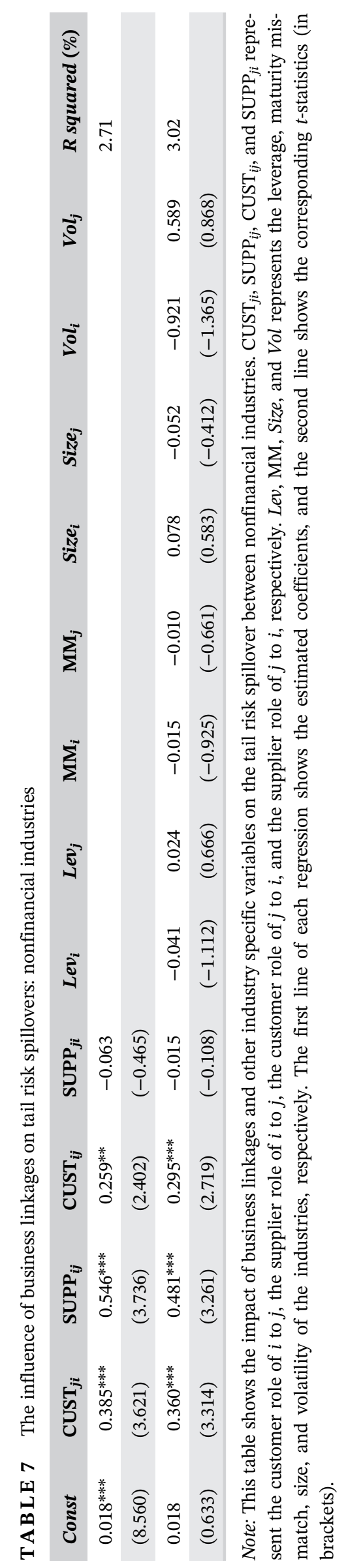


the $R$-squared coefficients in the regressions of restricted samples of closely linked pairs are significantly higher than that of the full sample. This is consistent with our hypothesis that business linkage is the main driver of tail risk spillover.

\section{4 | Business linkages and tail risk spillovers between nonfinancial industries}

Financial industries are commonly known as influential industries, since their risk is expected to easily and strongly propagate to other industries in the economy. Thus, to examine the impact of business linkages on tail risk transmission without the possible influence of the financial sector, we eliminate from our sample five industries in the financial services, including Federal Reserve Bank, credit intermediation and related activities (FED); Securities, commodity contracts and investments (INV); Insurance carriers and related activities (INS); Funds, trusts, and other financial vehicles (FUND); Real estate (RE); and Rental and leasing services and lessors of intangible assets (RL). The results of the cross-sectional regression reported in Table 7 are similar to our main findings, showing significant impacts of economic relationships on the tail risk transmission between industries. In addition, the tail risk spillover from an industry to its partner is significantly affected by the supplier role of the industry. We also observe a slight increase in the Rsquared coefficient as compared to the standard framework. Thus, this is a solid evidence that tail risk spillover stems from the actual trade flows rather than from the comovement with the financial sector.

\section{5 | CONCLUSION}

Tail risk connectedness has recently gained attention due to their important implication in risk management practise. In this paper, we construct the complete tail risk connectedness network among all industries in the US economy using the LASSO quantile regression technique developed by Belloni and Chernozhukov (2011) and Hautsch et al. (2015). Our results suggest a sophisticated tail risk connectedness network between US industries. We reveal important tail risk drivers whose shocks can influence many other industries, as well as tail risk receivers which are sensitive to shock spillovers from their partners. Since shocks from risk driver industries are likely to be the source of the instability of the whole economic system, our findings are useful for policy makers to properly regulate relevant industries. It is prerequisite that when considering a certain policy change in a specific sector or industry, policy makers are aware of possible impact on other related industries and the whole economy. Furthermore, understanding channels that tail events propagate through the system is essential for regulators to have prompt actions to prevent the snowball effects. Business managers can benefit from our findings of tail risk connectedness network by observing and predicting shocks transmitted to and from their trading partners to make informed decisions and alter their trade strategies. Investors and portfolio managers can incorporate the tail dependence between industries into their portfolio risk models and, as a result, achieve better tail risk prediction and more efficient asset allocation.

More importantly, we reveal the underlying economic rationale of the tail risk interdependence network. Using the Input-Output Accounts provided by the Bureau of Economic Analysis to measure the strength of business relationships between US industries, we show that business linkage is the main driver of the tail risk spillover network. Our findings are in line with the theoretical framework proposed by Acemoglu et al. (2017). This adds another layer of information available to practitioners in tail risk management. By better understanding the determinants of the tail risk network, investors, managers, and policy makers can make ex-ante prediction about the sensitivity of a particular business to external shocks given its trade practise with other industries.

Our findings are relevant for future research in two directions. The first direction is to examine the impacts of business linkages on tail risk spillovers between firms. Since US public companies are required to identify their main customers, we can obtain the information of firms in the supplier-customer relationship. This investigation will reveal if business linkages also influence the tail risk spillovers at firm level. Another direction is to examine the impact of business linkages on international tail risk transmission. This may shed the light on the important question regarding the true mechanism of tail risk spillovers between markets, whether it is trade flow or capital flow. This provides essential understanding for regulators in protecting and nurturing their home market.

\section{DATA AVAILABILITY STATEMENT}

The data that support the findings of this study are available from the corresponding author upon reasonable request.

\section{ORCID}

Linh H. Nguyen (1) https://orcid.org/0000-0002-4719-8582 Linh X. D. Nguyen (D) https://orcid.org/0000-0002-01740399

Linzhi Tan (1) https://orcid.org/0000-0001-6986-1923 


\section{ENDNOTES}

${ }^{1}$ We obtain qualitatively similar results if we use 1 and $5 \%$ quantile for loss exceedance. Summary results are available upon request.

2 The accounting data are available quarterly. In a quarter, each firm in an industry may have different report date. When aggregating their data to create the representative firm of the industry, we assume that the accounting data of the representative firm is obtained at the end date of a quarter. The underlying assumption is that the values of the accounting variables of the constituent firms do not change much during a quarter. This is a justifiable assumption given that we only use balance sheet data to construct industry characteristics.

${ }^{3}$ Although most of the coefficients are positive, there are cases when the spillover coefficients are negative, implying a hedging relationship between the two industries. In other words, some industries may benefit from the distress of the other industries. The hedging relationship in industry pairs is justifiable by looking at the nature of their businesses. For example, shocks to many industries have negative influence on the tail risk of legal service industry, which is reasonable since legal service should have more business opportunities when other industries are in distress.

${ }^{4}$ In this calculation, we apply the assumption in Ahern and Harford (2014) and Becker and Thomas (2011) that market shares are constant for every use of commodity. To demonstrate, if $60 \%$ of the total supply of commodity $c$ is produced by industry $i$ (i.e., SHARE $_{i c}=0.6$ ), then industry $j$ purchases $60 \%$ of its commodity $c$ input from industry $i$.

${ }^{5}$ While labour (referred to as employee compensation in the Use table) is an important input, there is no Labour industry in the Make table. Thus, we follow Ahern and Harford (2014) to create an artificial Labour industry in the Use table. This step is only to ensure that the input values are accurately calculated. The industry will not be included in the final sample for investigation.

${ }^{6}$ The IO tables are updated every 5 years (year ending 2 and 7). BEA provides estimated tables for other years.

\section{REFERENCES}

Acemoglu, D., Ozdaglar, A., \& Tahbaz-Salehi, A. (2017). Microeconomic origins of macroeconomic tail risks. American Economic Review, 107(1), 54-108.

Adams, Z., Füss, R., \& Gropp, R. (2014). Spillover effects among financial institutions: A state-dependent sensitivity value-atrisk approach. Journal of Financial and Quantitative Analysis, 49(3), 575-598.

Adrian, T., \& Brunnermeier, M. K. (2016). CoVaR. American Economic Review, 106(7), 1705-1741.

Ahern, K.R., 2013. Network centrality and the cross section of stock returns. Working Paper. Retrieved from SSRN https://ssrn. com/abstract $=2197370$

Ahern, K. R., \& Harford, J. (2014). The importance of industry links in merger waves. Journal of Finance, 69(2), 527-576.

Ang, A., \& Chen, J. (2002). Asymmetric correlation of equity portfolios. Journal of Financial Economics, 63(3), 443-494.

Bae, K. H., Karolyi, G. A., \& Stulz, R. M. (2003). A new approach to measuring financial contagion. Review of Financial Studies, 16 (3), 717-763.
Bali, T. G., Demirtas, K. O., \& Levy, H. (2009). Is there an Intertemporal relation between downside risk and expected returns? Journal of Financial and Quantitative Analysis, 44(4), 883-909.

Baumeister, C., \& Kilian, L. (2016). Forty years of oil price fluctuations: Why the price of oil may still surprise us. Journal of Economic Perspectives, 30(1), 139-160.

Becker, M.J. and Thomas, S.E., 2011. Changes in concentration across vertically related industries. Working Paper. Retrieved from SSRN https://ssrn.com/abstract $=1816638$

Beine, M., Cosma, A., \& Vermeulen, R. (2010). The dark side of global integration: Increasing tail dependence. Journal of Banking and Finance, 34(1), 184-192.

Belloni, A., \& Chernozhukov, V. (2011). L1-penalized Quantile regression in high-dimensional sparse models. The Annals of Statistics, 39(1), 82-130.

Benoit, S., Colliard, J. E., Hurlin, C., \& Pérignon, C. (2017). Where the risks lie: A survey on systemic risk. Review of Finance, 21 (1), 109-152.

Betz, F., Hautsch, N., Peltonen, T. A., \& Schienle, M. (2016). Systemic risk spillovers in the European banking and sovereign network. Journal of Financial Stability, 25, 206-224.

Billio, M., Getmansky, M., Lo, A. W., \& Pelizzon, L. (2012). Econometric measures of connectedness and systemic risk in the finance and insurance sectors. Journal of Financial Economics, 104(3), 535-559.

Bollerslev, T., \& Todorov, V. (2011). Tails, fears, and risk Premia. Journal of Finance, 66(6), 2165-2211.

Cappiello, L., Gérard, B., Kadareja, A., \& Manganelli, S. (2014). Measuring Comovements by regression quantiles. Journal of Financial Econometrics, 12(4), 645-678.

Chabi-Yo, F., Ruenzi, S., \& Weigert, F. (2018). Crash sensitivity and the cross section of expected stock returns. Journal of Financial and Quantitative Analysis, 53(3), 1059-1100.

Chiu, W. C., Pena, J. I., \& Wang, C. W. (2015). Industry characteristics and financial risk contagion. Journal of Banking and Finance, 50, 411-427.

Christiansen, C., \& Ranaldo, A. (2009). Extreme coexceedances in new EU member states' stock markets. Journal of Banking and Finance, 33(6), 1048-1057.

Cohen, L., \& Frazzini, A. (2008). Economic links and predictable returns. Journal of Finance, 63(4), 1977-2011.

Forbes, K., \& Chinn, M. (2004). A decomposition of global linkages in financial markets over time. The Review of Economics and Statistics, 86(3), 705-722.

Gabaix, X. (2011). The granular origins of aggregate fluctuations. Econometrica, 79(3), 733-772.

Giglio, S., Kelly, B., \& Pruitt, S. (2016). Systemic risk and the macroeconomy: An empirical evaluation. Journal of Financial Economics, 119(3), 457-471.

Härdle, W. K., Wang, W., \& Yu, L. (2016). TENET: Tail-Event driven NETwork risk. Journal of Econometrics, 192(2), 499-513.

Harris, R. D. F., Nguyen, L. H., \& Stoja, E. (2019). Systematic extreme downside tail risk. Journal of International Financial Markets, Institutions and Money, 61, 128-142.

Hartmann, P., Straetmans, S. and De Vries, C., 2005. Banking system stability: A cross-Atlantic perspective. ECB Working Paper, No. 527.

Hartmann, P., Straetmans, S., \& De Vries, C. G. (2004). Asset market linkages in crisis periods. Review of Economics and Statistics, 86(1), 313-326. 
Hautsch, N., Schaumburg, J., \& Schienle, M. (2014). Forecasting systemic impact in financial networks. International Journal of Forecasting, 30(3), 781-794.

Hautsch, N., Schaumburg, J., \& Schienle, M. (2015). Financial network systemic risk contributions. Review of Finance, 19(2), 685-738.

Hong, Y., Liu, Y., \& Wang, S. (2009). Granger causality in risk and detection of extreme risk spillover between financial markets. Journal of Econometrics, 150(2), 271-287.

Huang, W., Liu, Q., Rhee, S. G., \& Wu, F. (2012). Extreme downside risk and expected stock returns. Journal of Banking and Finance, 36(5), 1492-1502.

Jarque, C., \& Bera, A. (1987). A test for normality of observations and regression residuals. International Statistical Review, 55(2), $163-172$.

Kelly, B., \& Jiang, H. (2014). Tail risk and asset prices. Review of Financial Studies, 27(10), 2841-2871.

Kenourgios, D., Samitas, A., \& Paltalidis, N. (2011). Financial crises and stock market contagion in a multivariate time-varying asymmetric framework. Journal of International Financial Markets, Institutions and Money, 21(1), 92-106.

Kilian, L. (2009). Not all oil price shocks are alike: Disentangling demand and supply shocks in the crude oil market. American Economic Review, 99(3), 1053-1069.

Li, Y., \& Giles, D. E. (2015). Modelling volatility spillover effects between developed stock markets and asian emerging stock markets. International Journal of Finance \& Economics, 20(2), 155-177.

Long, J. B., \& Plosser, C. (1983). Real business cycles. Journal of Political Economy, 91(1), 39-69.
Madaleno, M., \& Pinho, C. (2012). International stock market indices comovements: A new look. International Journal of Finance \& Economics, 17(1), 89-102.

Meine, C., Supper, H., \& Weib, G. N. F. (2016). Is tail risk priced in credit default swap Premia? Review of Finance, 20(1), 287-336.

Pouliasis, P., Kyriakou, I., \& Papapostolou, N. (2017). On equity risk prediction and tail spillovers. International Journal of Finance \& Economics, 22(4), 379-393.

Pouliasis, P., Papapostolou, N., Kyriakou, I., \& Visvikis, I. (2018). Shipping equity risk behavior and portfolio management. Transportation Research Part A: Policy and Practice, 116, 178-200.

Reboredo, J. (2015). Is there dependence and systemic risk between oil and renewable energy stock prices? Energy Economics, 48, $32-45$.

Shea, J. (2002). Complementarities and Comovements. Journal of Money, Credit and Banking, 34(2), 412-433.

Wang, G. J., Xie, C., He, K., \& Stanley, H. E. (2017). Extreme risk spillover network: Application to financial institutions. Quantitative Finance, 17(9), 1417-1433.

How to cite this article: LH Nguyen, LXD Nguyen, L Tan. Tail risk connectedness between US industries. Int J Fin Econ. 2020;1-27. https:// doi.org/10.1002/ijfe.1979 


\section{APPENDIX A: SELECTING THE PENALTY PARAMETER $\lambda$ FOR THE LASSO QUANTILE REGRESSION}

We determine $\lambda$ for each industry in a data driven way that maximizes the backtesting performance of the estimated VaR of the industry. Specifically, for an industry $i$, we carry out the following steps:

Step 1: For each $c$ in the $\nu$-equidistant grid $C=\left\{c_{1}<\cdots<c_{k}=c_{1}+(k-1) \nu<\cdots<c_{L}\right\}$, we determine the penalty parameter $\lambda(c)$ using four following steps.

- Step 1a. Take $T$ i.i.d. draw from the Uniform distribution $U[0,1]$ independent of the timing of the dataset of the regression, denoted as $u_{1}, u_{2}, \cdots, u_{T}$. Calculate the following variable:

$$
\Lambda=T \times \max _{1 \leq k \leq K} \frac{1}{T}\left|\sum_{t=1}^{T} \frac{W_{t, k}^{i}\left(q-I\left(u_{t} \leq q\right)\right)}{\hat{\sigma_{k}} \sqrt{q(1-q)}}\right|
$$

- Step 1b. Repeat Step 1a for 500 times to obtain an empirical distribution of $\Lambda$, conditional on the value of $\boldsymbol{W}^{i}$. Given a confidence level $1-\alpha$, the penalty parameter is calculated as

$$
\lambda(c)=c \times Q(\Lambda, 1-\alpha)
$$

where $Q(\Lambda, 1-\alpha)$ is the $1-\alpha$ quantile of the empirical distribution of $\Lambda$. We follow Belloni and Chernozhukov (2011) suggestion and set $\alpha=0.1$.

- Step 1c. Estimate the $l_{1}$-penalized quantile regression according to Equation (5) and retain only variables in $\boldsymbol{W}^{i}$ whose absolute value is greater than 0.0001 . Using the remaining variables, estimate the post-LASSO quantile regression to obtain the corresponding postLASSO estimated coefficients and the fitted value of the quantile (VaR) of the dependent variable over time.

- Step 1d. Backtest the estimated VaR using Hautsch et al. (2015) log likelihood ratio test: obtain the VaR exceedance series $\operatorname{VE}_{t}=I\left(X_{t}^{i}<V a \hat{R}_{q, t}\right)$ and estimate the logistic regression model:

$$
\mathrm{VE}_{t}=\theta_{0}+\left(\mathrm{VE}_{t-1}, \mathrm{VE}_{t-2}, \mathrm{VE}_{t-3}, V a \hat{R_{q, t-1}}\right) \boldsymbol{\theta}+\varepsilon_{t}=\theta_{0}
$$$$
+\boldsymbol{V}_{t}^{\prime} \boldsymbol{\theta}+\varepsilon_{t}
$$

The log likelihood ratio test statistic for the null hypothesis that the VaR exceedance is i.i.d. Bernoulli distributed with success probability $q$ is

$$
L R=-2\left(\ln \mathscr{L}_{r}-\ln \mathscr{L}_{u}\right)^{a} \tilde{\chi}_{5}^{2}
$$

where

$$
\begin{gathered}
\ln \mathcal{L}_{u}=\sum\left[\mathrm{VE}_{t} \ln F_{\log }\left(\theta_{0}+\boldsymbol{V}_{t}^{\prime} \boldsymbol{\theta}\right)+\left(1-\mathrm{VE}_{t}\right)\right. \\
\left.\ln \left(1-F_{\log }\left(\theta_{0}+\boldsymbol{V}_{t}^{\prime} \boldsymbol{\theta}\right)\right)\right] \\
\ln \mathcal{L}_{r}=\sum \mathrm{VE}_{t} \ln (q)+\left(T-\sum \mathrm{VE}_{t}\right) \ln (1-q)
\end{gathered}
$$

and $F_{\log }\left(\theta_{0}+\boldsymbol{V}_{t}^{\prime} \boldsymbol{\theta}\right)$ is the fitted value of the logistic regression. Obtain the $p$-value of the test $p(c)$.

Step 2. Repeat step 1 for every $c$ in the $C$ grid and select the $c$ that produces the highest $p(c)$ to be the optimal value of $c$. The corresponding value of the penalty parameter is the optimal $\lambda$ for the LASSO quantile regression.

\section{APPENDIX B: LIST OF US INDUSTRIES}

\begin{tabular}{|lll|}
\hline No & Full name & Abbreviation \\
\hline 1 & Farms & FARM \\
\hline 2 & Oil and gas extraction & OG \\
\hline 3 & Mining, except oil and gas & MNG \\
\hline 4 & Support activities for mining & MNGS \\
\hline 5 & Utilities & UTL \\
\hline 6 & Construction & CTN \\
\hline 7 & Wood products & WP \\
\hline 8 & Nonmetallic mineral products & MNR \\
\hline 9 & Primary metals & MTL \\
\hline 10 & Fabricated metal products & FMTL \\
\hline 11 & Machinery & MCN \\
\hline 12 & Computer and electronic products & CPT \\
\hline 13 & Electrical equipment, appliances, and & ELT \\
& components & \\
\hline 14 & Motor vehicles, bodies and trailers, and & MOTP \\
& parts & \\
\hline 15 & Other transportation equipment & OTPE \\
\hline 16 & Furniture and related products & FURN \\
\hline 17 & Miscellaneous manufacturing & MMFG \\
\hline 18 & Food and beverage and tobacco & FB \\
& products & \\
\hline
\end{tabular}




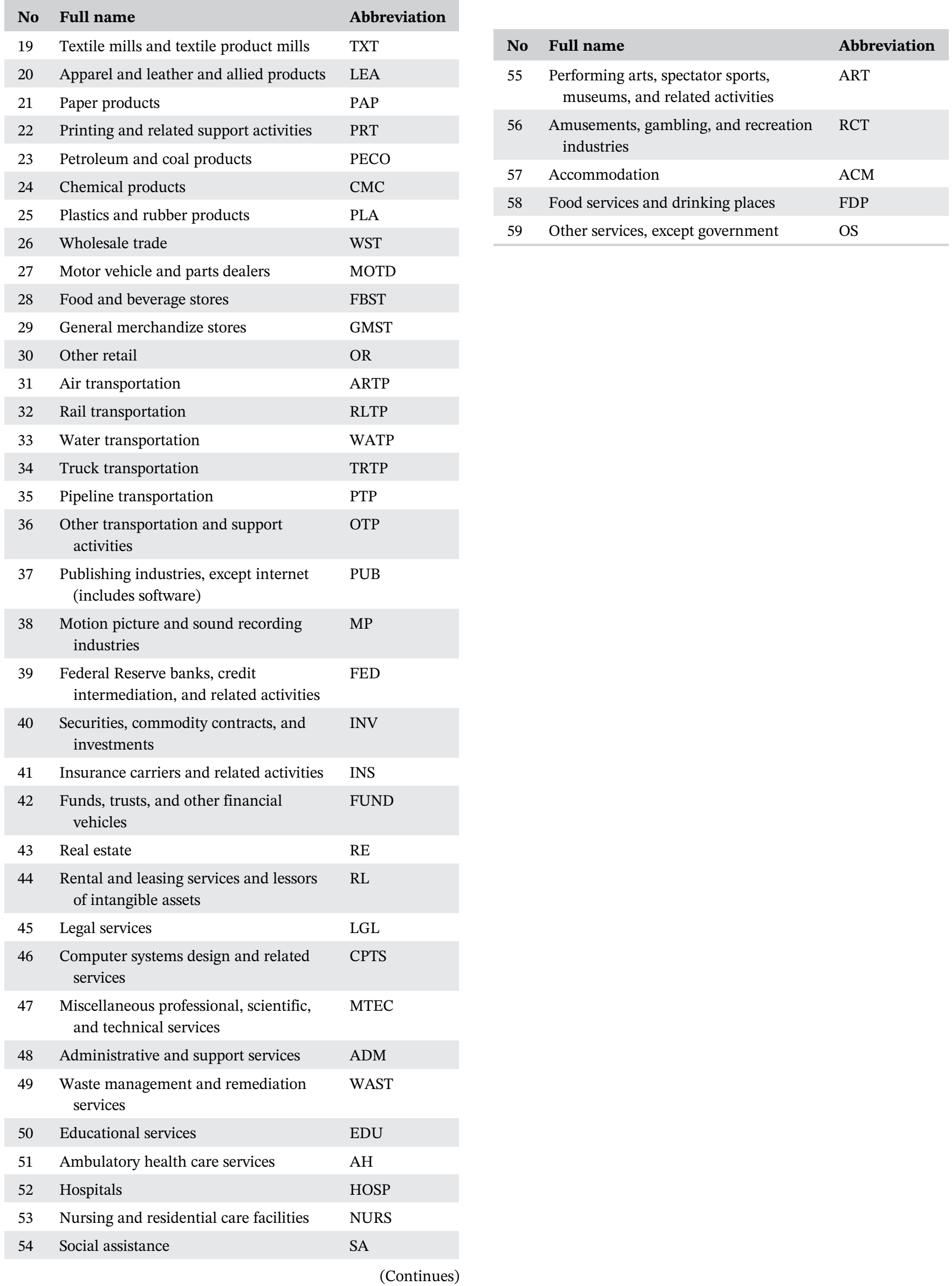


APPENDIX C: SUMMARY STATISTIC OF US INDUSTRIES

This appendix shows the mean, standard deviation, skewness, and kurtosis of the returns of each industry in our sample from January 2005 to December 2016.
The Jarque and Bera (1987) test statistic for the normality test of the returns of each industry is also reported. The appendix also contains the average value of the specific characteristics of each industry during the examined period. See Appendix B for the full names of the industries.

\begin{tabular}{|c|c|c|c|c|c|c|c|c|c|}
\hline Industry & Mean & $\begin{array}{l}\text { Standard } \\
\text { deviation }\end{array}$ & Skewness & Kurtosis & $\begin{array}{l}\text { Jarque-Bera } \\
\text { test statistic }\end{array}$ & $\begin{array}{l}\text { Average } \\
\text { leverage }\end{array}$ & $\begin{array}{l}\text { Average } \\
\text { maturity } \\
\text { mismatch }\end{array}$ & $\begin{array}{l}\text { Average } \\
\text { size }\end{array}$ & $\begin{array}{l}\text { Average } \\
\text { weekly } \\
\text { volatility }\end{array}$ \\
\hline FARM & 0.003 & 0.042 & 0.017 & 4.944 & 98.718 & 2.090 & -0.104 & 9.306 & 0.017 \\
\hline OG & 0.002 & 0.045 & -0.622 & 8.194 & 745.065 & 2.210 & -0.065 & 13.634 & 0.019 \\
\hline MNG & 0.002 & 0.050 & -0.059 & 6.515 & 323.208 & 2.068 & -0.129 & 12.515 & 0.020 \\
\hline MNGS & 0.002 & 0.050 & -0.685 & 7.840 & 661.094 & 1.893 & -0.118 & 12.344 & 0.020 \\
\hline UTL & 0.002 & 0.022 & -1.393 & 14.076 & $3,407.663$ & 3.777 & 0.018 & 15.127 & 0.009 \\
\hline CTN & 0.001 & 0.047 & 0.820 & 10.376 & $1,491.364$ & 3.242 & -0.087 & 12.358 & 0.018 \\
\hline WP & 0.001 & 0.046 & 0.140 & 10.577 & $1,501.788$ & 2.646 & -0.133 & 9.386 & 0.017 \\
\hline MNR & 0.002 & 0.046 & -0.139 & 7.194 & 461.479 & 3.015 & -0.017 & 11.889 & 0.017 \\
\hline MTL & 0.002 & 0.047 & -0.004 & 8.423 & 768.285 & 2.419 & -0.039 & 12.693 & 0.018 \\
\hline FMTL & 0.003 & 0.032 & -0.270 & 7.401 & 513.722 & 3.166 & -0.068 & 11.554 & 0.012 \\
\hline $\mathrm{MCN}$ & 0.002 & 0.035 & 0.134 & 8.312 & 739.181 & 2.907 & 0.012 & 12.969 & 0.013 \\
\hline $\mathrm{CPT}$ & 0.002 & 0.028 & -0.333 & 5.696 & 201.478 & 1.944 & -0.408 & 14.125 & 0.011 \\
\hline ELT & 0.002 & 0.031 & -0.182 & 6.082 & 251.606 & 2.806 & -0.146 & 11.755 & 0.013 \\
\hline MOTP & 0.002 & 0.041 & -0.077 & 7.202 & 461.815 & 3.643 & 0.079 & 13.971 & 0.015 \\
\hline OTPE & 0.003 & 0.029 & -0.456 & 6.768 & 392.682 & 4.181 & -0.092 & 12.932 & 0.011 \\
\hline FURN & 0.001 & 0.043 & 0.186 & 6.377 & 301.572 & 2.389 & -0.091 & 9.760 & 0.016 \\
\hline MMFG & 0.002 & 0.023 & -1.061 & 10.388 & $1,543.471$ & 1.872 & -0.351 & 11.884 & 0.009 \\
\hline FB & 0.002 & 0.018 & -1.470 & 16.577 & $5,041.553$ & 3.085 & -0.007 & 13.639 & 0.007 \\
\hline TXT & 0.002 & 0.048 & 0.512 & 9.762 & $1,221.857$ & 2.301 & 0.032 & 9.353 & 0.016 \\
\hline LEA & 0.002 & 0.034 & 0.033 & 7.080 & 435.013 & 2.040 & -0.128 & 11.802 & 0.013 \\
\hline PAP & 0.002 & 0.026 & -0.315 & 6.502 & 330.702 & 3.020 & -0.012 & 12.284 & 0.011 \\
\hline PRT & 0.001 & 0.036 & -0.219 & 7.543 & 544.213 & 3.795 & -0.020 & 10.000 & 0.013 \\
\hline PECO & 0.002 & 0.030 & -0.790 & 8.556 & 871.832 & 2.036 & -0.066 & 14.678 & 0.013 \\
\hline CMC & 0.002 & 0.021 & -0.899 & 10.747 & $1,652.280$ & 2.287 & -0.169 & 14.437 & 0.009 \\
\hline PLA & 0.002 & 0.037 & 0.003 & 8.667 & 838.946 & 5.228 & -0.044 & 11.010 & 0.013 \\
\hline WST & 0.002 & 0.024 & -0.627 & 8.772 & 911.360 & 3.178 & -0.046 & 13.036 & 0.009 \\
\hline MOTD & 0.003 & 0.034 & 0.597 & 12.567 & $2,428.518$ & 3.729 & 0.228 & 10.772 & 0.013 \\
\hline FBST & 0.002 & 0.029 & -0.085 & 4.822 & 87.513 & 2.829 & -0.071 & 11.636 & 0.012 \\
\hline GMST & 0.001 & 0.024 & -0.432 & 6.955 & 428.286 & 2.636 & -0.035 & 12.809 & 0.010 \\
\hline OR & 0.002 & 0.028 & -0.088 & 6.933 & 404.845 & 2.429 & -0.062 & 13.376 & 0.011 \\
\hline ARTP & 0.003 & 0.053 & 0.237 & 6.418 & 311.035 & 14.286 & -0.113 & 12.868 & 0.021 \\
\hline RLTP & 0.004 & 0.037 & -0.237 & 5.113 & 122.515 & 2.252 & -0.022 & 12.322 & 0.015 \\
\hline WATP & 0.001 & 0.039 & -0.477 & 8.143 & 714.683 & 2.364 & 0.007 & 12.059 & 0.015 \\
\hline TRTP & 0.002 & 0.037 & 0.129 & 4.812 & 87.517 & 2.974 & -0.014 & 10.007 & 0.015 \\
\hline PTP & 0.003 & 0.038 & -0.575 & 8.871 & 935.201 & 2.934 & 0.011 & 13.045 & 0.014 \\
\hline OTP & 0.001 & 0.029 & 0.010 & 5.556 & 170.659 & 2.581 & -0.111 & 11.612 & 0.012 \\
\hline
\end{tabular}




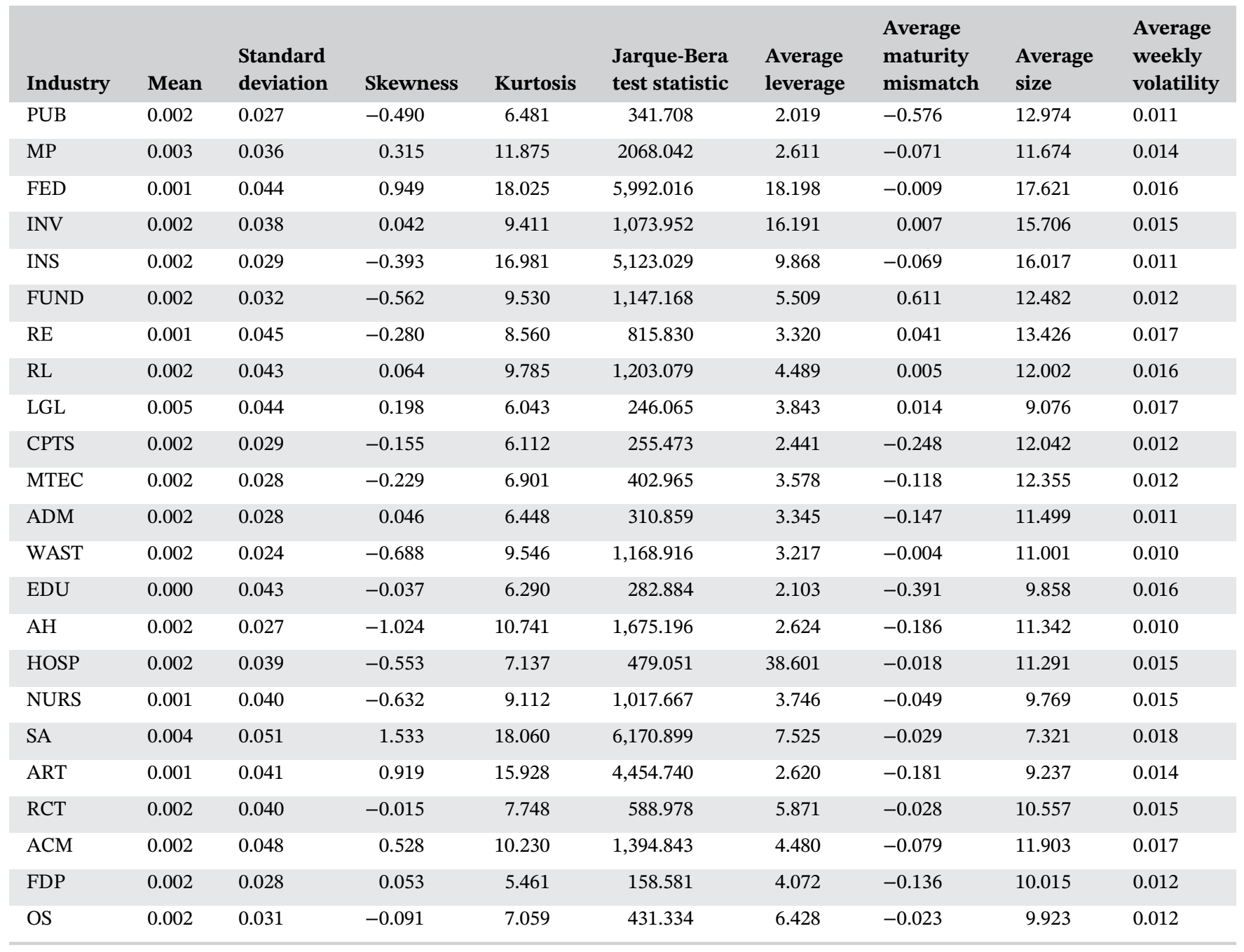




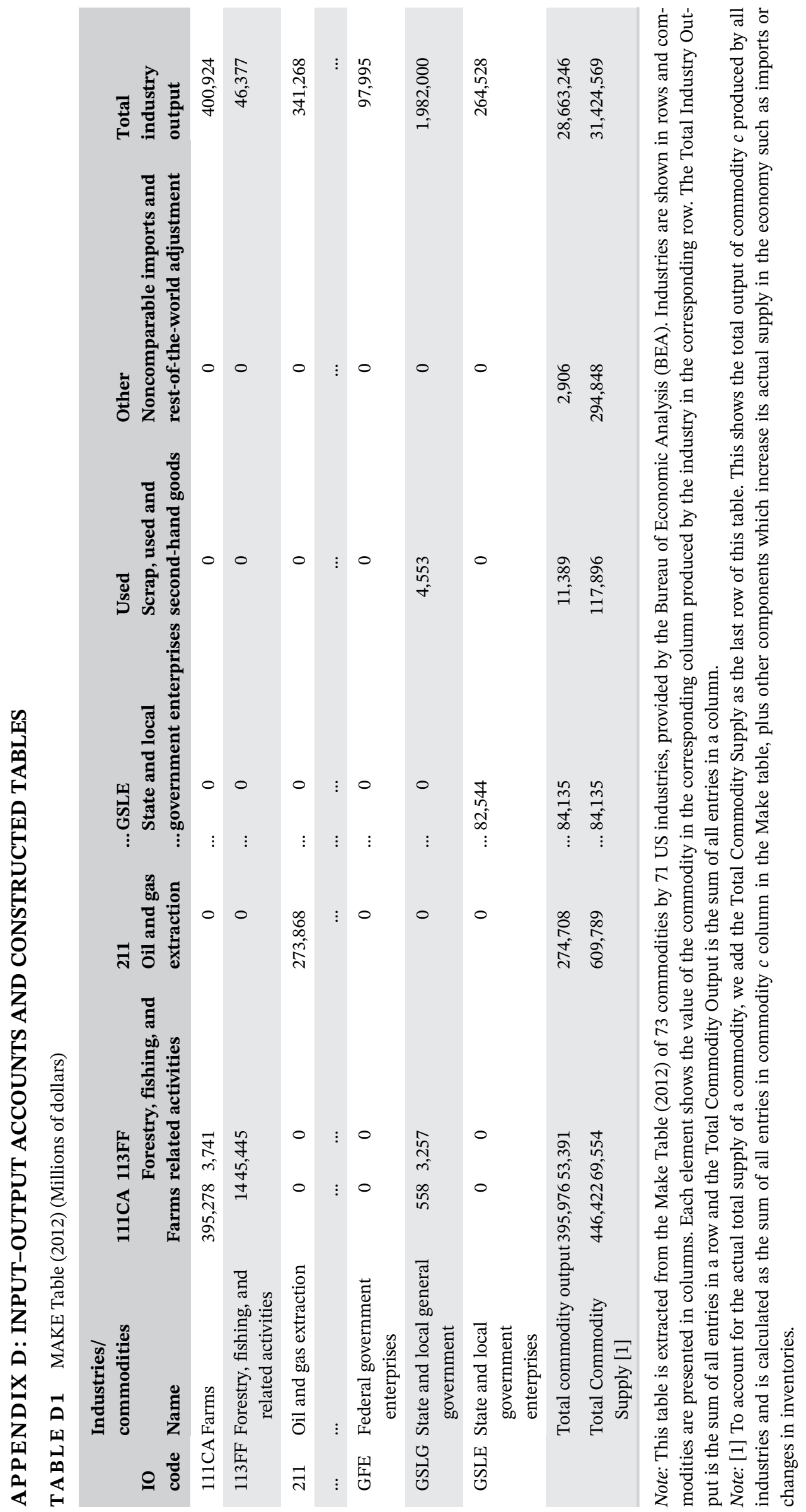




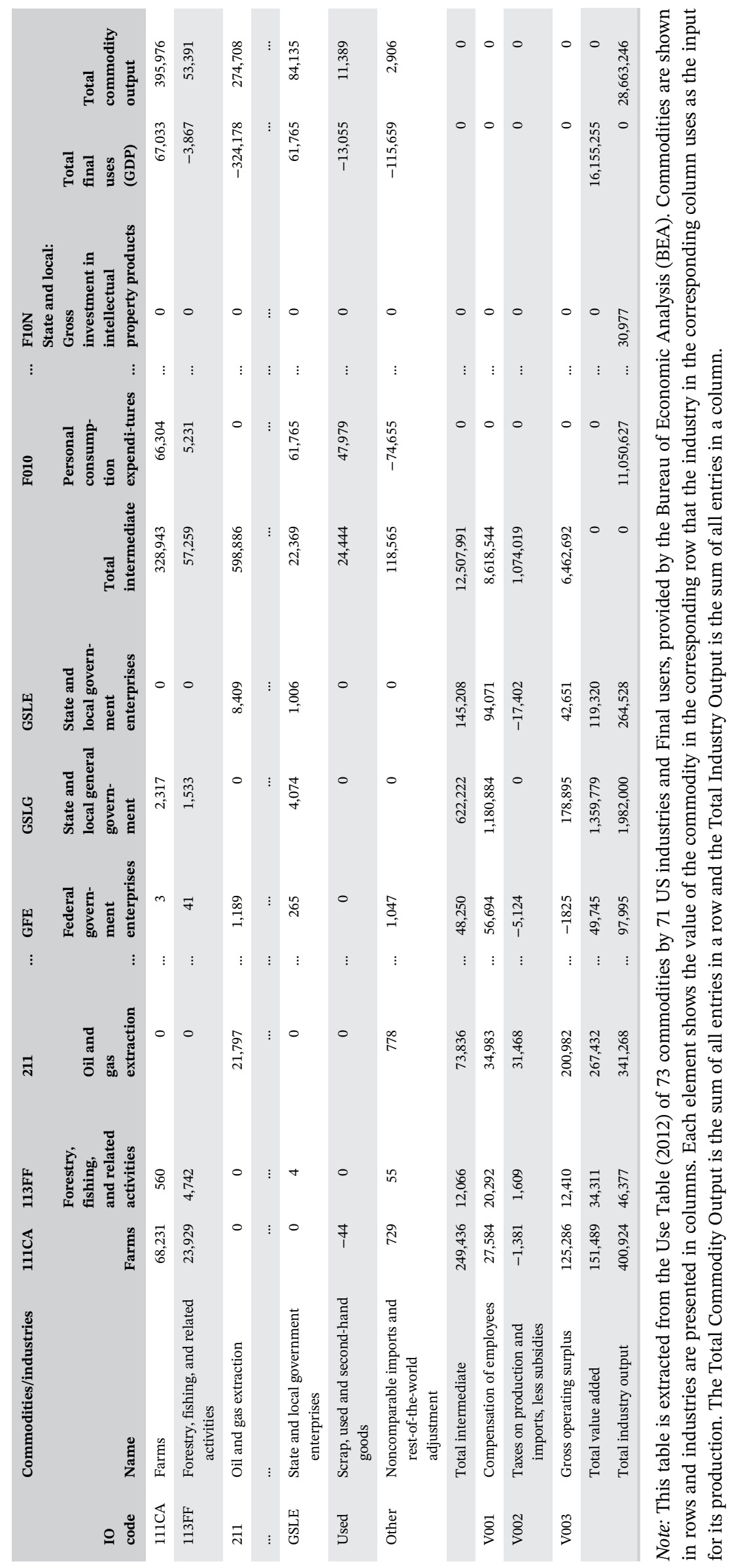



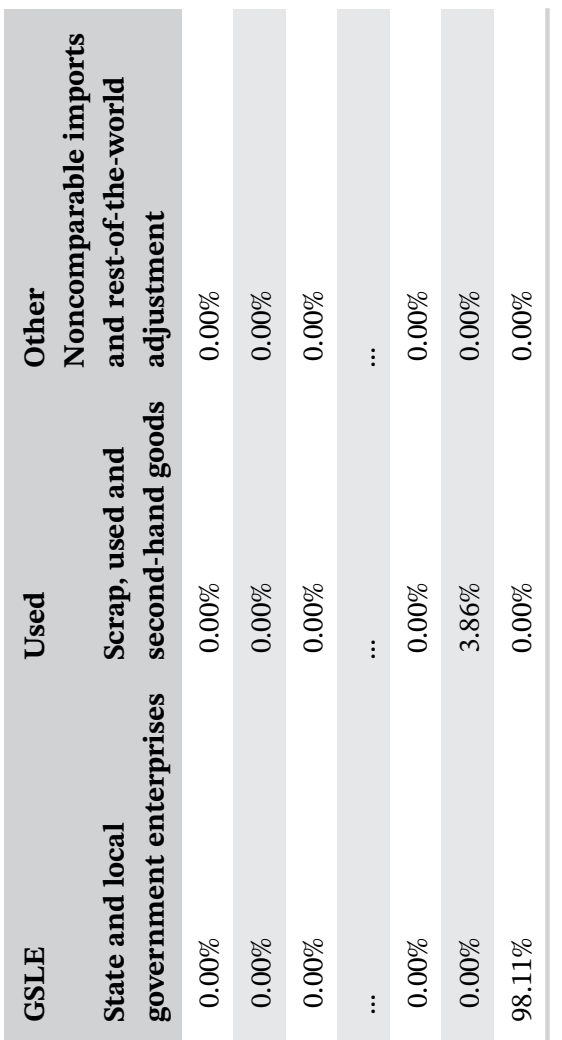

害富

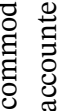

पू

글

के

o :

क्षे

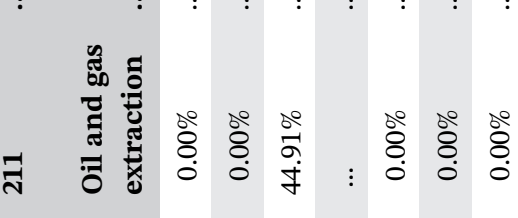

赵事

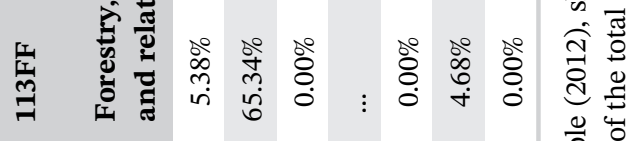

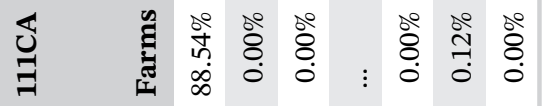

음

ㄴ․․․

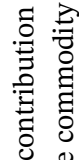

艺

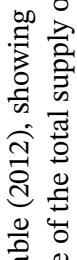

至

昰悹

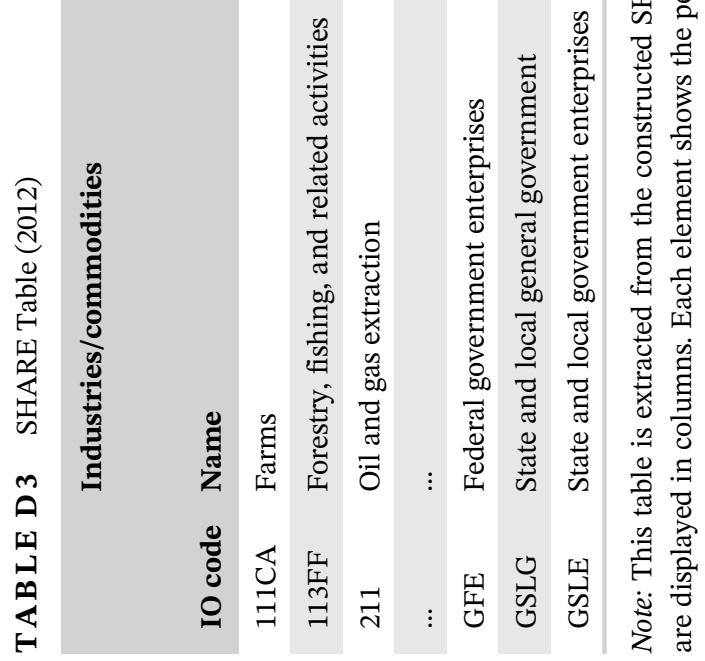

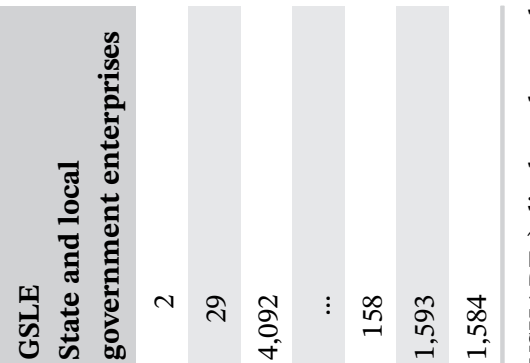
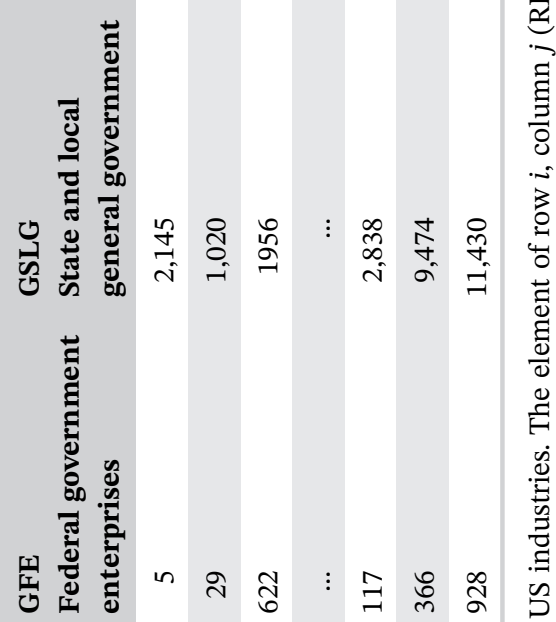

$\begin{array}{llllllllll}\vdots & \vdots & \vdots & \vdots & \vdots & \vdots & \vdots & \vdots & \vdots & \Phi\end{array}$
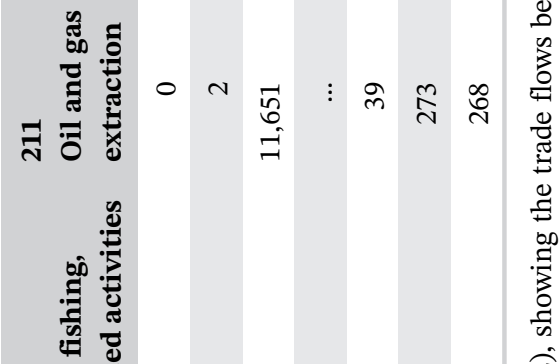

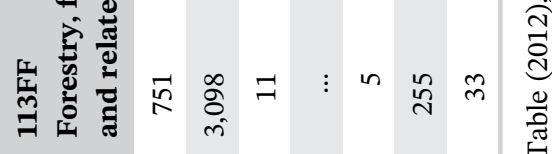

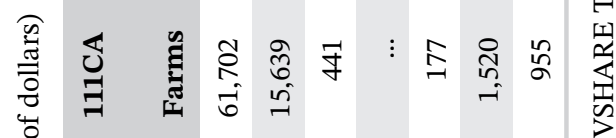

章

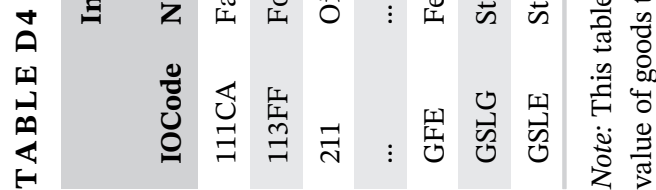




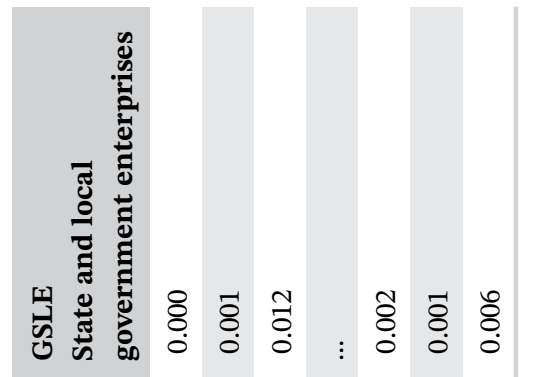

1
0
0
0
0
0
0
0
0
0
0
0
0
0
0
0
0

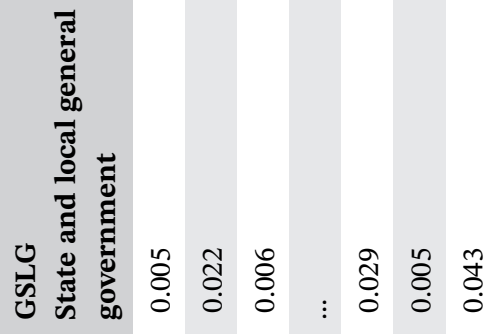

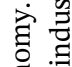

응

㔄

$\Xi$

宽.

हี

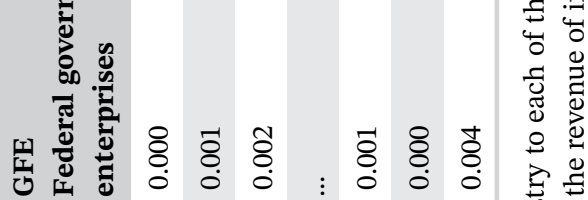

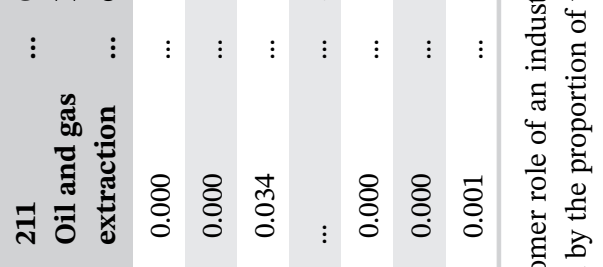

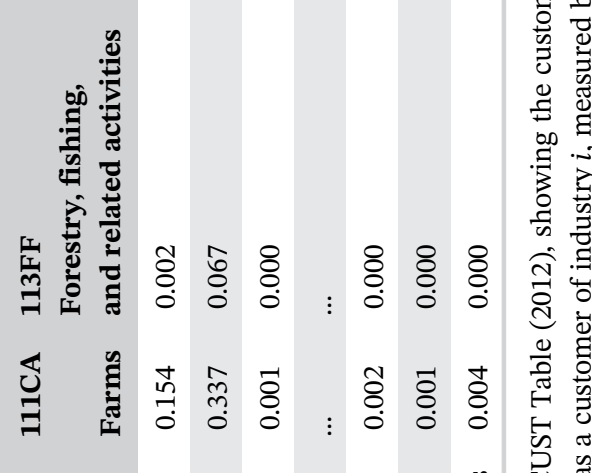

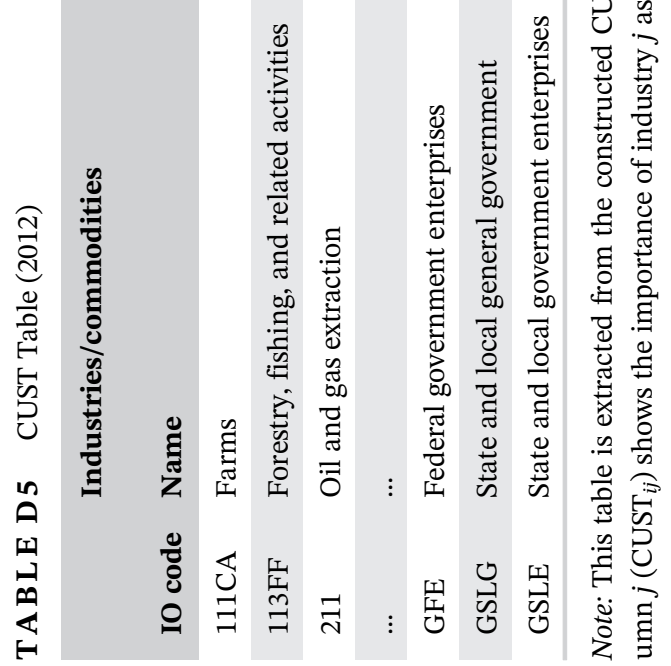

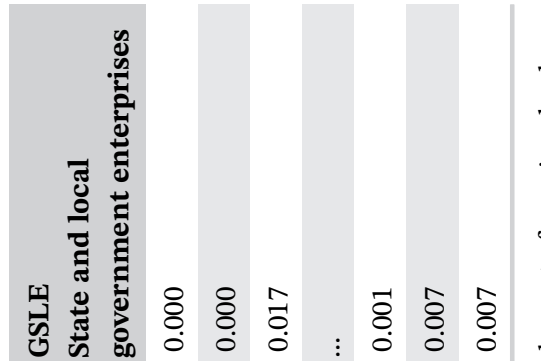

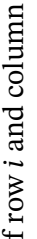

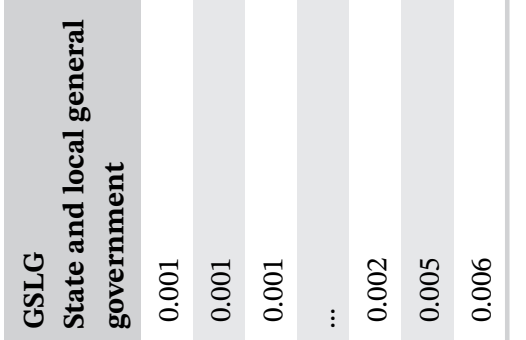

$\stackrel{2}{2}$

局苞

宛

ํํㅇ

ర్

.$\Xi$

.

莫

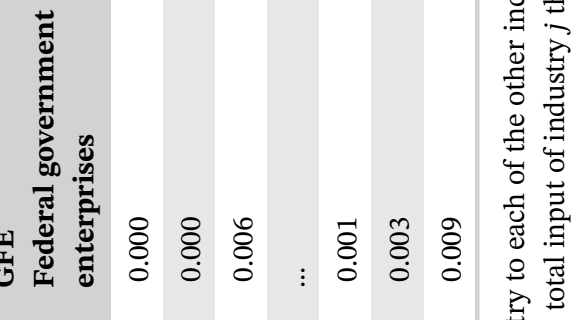

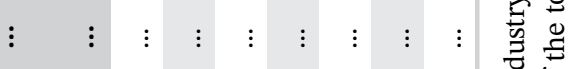

茲

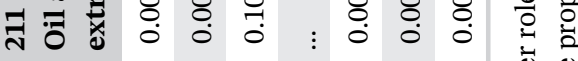

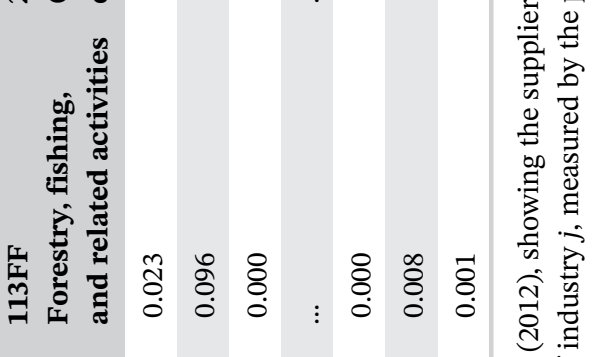

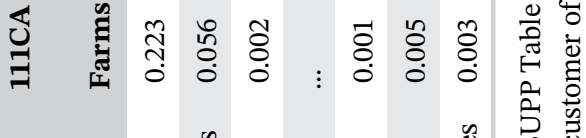

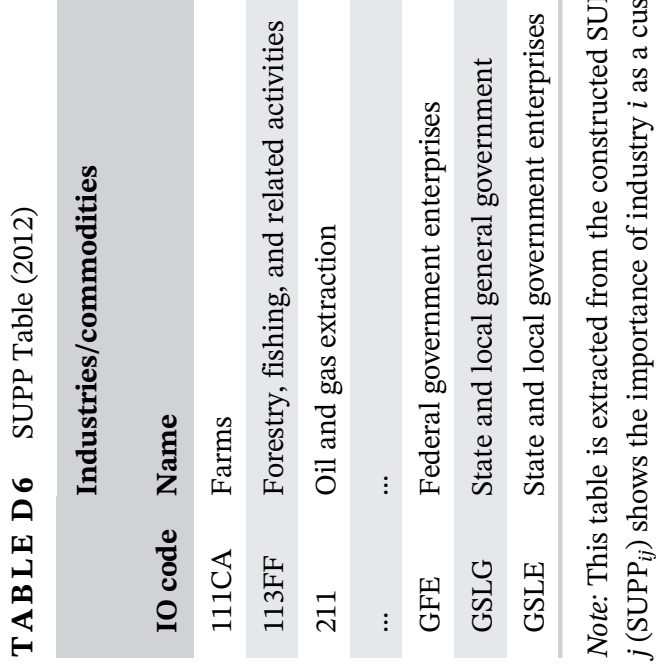

